\title{
Artificial Neural Network-Particle Swarm Optimization (ANN-PSO) Approach for Behaviour Prediction and Structural Optimization of Lightweight Sandwich Composite Heliostats
}

\author{
Sulaiman O. Fadlallah ${ }^{1} \cdot$ Timothy N. Anderson ${ }^{2} \cdot$ Roy J. Nates ${ }^{2}$ \\ Received: 6 April 2021 / Accepted: 18 August 2021 / Published online: 4 September 2021 \\ (c) Crown 2021
}

\begin{abstract}
The necessity to diminish the heliostats' cost so that central tower concentrating solar power (CSP) systems can stride to the forefront to become the technology of choice for generating renewable electricity is obliging the industry to consider innovative designs, leading to new materials being implemented into the development of heliostats. Honeycomb sandwich composites offer a lightweight but stiff structure that appear to be an ideal substitute for existing heliostat mirrors and their steel supporting trusses, avoiding large drive units and reducing energy consumption. However, realizing a honeycomb sandwich composite as a heliostat, among a multitude of possible combinations can be tailored from, that delivers the best trade-off between the panel's weight reduction (broadly equates to cost) and structural integrity is cumbersome and challenging due to the complex nonlinear material behaviour, along with the large number of design variables and performance constraints. We herein offer a simulation-optimization model for behaviour prediction and structural optimization of lightweight honeycomb sandwich composite heliostats utilizing artificial neural network (ANN) technique and particle swarm optimization (PSO) algorithm. Considering various honeycomb core configurations and several loading conditions, a thorough investigation was carried out to optimally choose the training algorithm, number of neurons in the hidden layer, activation function in a network and the suitable swarm size that delivers the best performance for convergence and processing time. Carried out for three case scenarios, each with different design requirements, the results showed that the proposed integrated ANN-PSO approach provides a useful, flexible and time-efficient tool for heliostat designers to predict and optimize the structural performance of honeycomb sandwich composite-based heliostats as per desired requirements. Knowing that heliostats in the field are not all subjected to the same wind conditions, this method offers flexibility to tailor heliostats independently, allowing them to be made lighter depending on the local wind speed in the field. This could lead to reductions in the size of drive units used to track the heliostat, and the foundations required to support these structures. Such reductions would deliver real cost savings, which are currently an impediment to the wider spread use of CSP systems.
\end{abstract}

Keywords Heliostat $\cdot$ Sandwich composite $\cdot$ Honeycomb $\cdot$ Fluid-structure interaction (FSI) $\cdot$ ANN $\cdot$ PSO

\section{Introduction}

Among all concentrating solar power (CSP) technologies [1-3], central-receiver tower CSP systems are one of the most promising renewable technologies for large-scale

Sulaiman O. Fadlallah

s.o.fadlallah@hud.ac.uk

1 School of Computing and Engineering, University of Huddersfield, Huddersfield, UK

2 Department of Mechanical Engineering, Auckland University of Technology, Auckland, New Zealand electricity production $[4,5]$. However, a key challenge to these systems is the large number of mirrored heliostats which represent up to 50\% of a CSP plant's cost [6]. This has motivated the development of innovative heliostat designs and solutions, intended to reduce the heliostats' cost without affecting its tracking performance [7-11].

One promising way of reducing the cost of heliostats would be to combine the mirror and its supporting structure into a single system. However, heliostats are constantly exposed to aerodynamic forces that can lead to structural deformations, affecting their optical performance. Therefore, one of the challenges in realizing this goal is ensuring they 
are able to cope with the aerodynamic loads imposed upon them during operation [12-15].

In this vein, sandwich composite materials offer a lightweight but stiff structure that appear to be an ideal substitute for existing heliostat mirrors and their supporting trusses [16-18]. Sandwich composites have been extensively adopted in the motorsport, construction, marine and aerospace industries [19-22] (applications where reducing weight whilst maintaining the stiffness is of key importance) due to their comparatively low-cost, high strength-to-weight ratio, corrosion-resistance and good energy-absorbing capabilities [23-26].

One common sandwich composite is the honeycomb core panel, whereby there are a large number of hexagonal voids for mass reduction, and the thickness of the core provides the stiffness. By relatively simple variations in cell geometry, and panel thickness, the properties of these panels can be tailored to the appropriate load conditions. In a recent study, the authors [27] characterized the wind loads that would be encountered on a heliostat for a range of wind conditions. Based on the findings of this study, it was apparent that a sandwich composite heliostat mirror might maintain its structural integrity, to the appropriate optical requirements, and for the typical aerodynamic loading conditions. However, no attempt was made to confirm this.

Now, realizing a honeycomb core sandwich composite as a heliostat is a trade-off between weight reduction (which broadly equates to cost) and its structural properties (which determine its optical performance). In this respect, the properties of the honeycomb core are highly dependent upon the honeycomb's cellular geometry [cell wall angle $(\varphi)$, cell wall length $(a)$ and cell wall thickness $(t)$ ] and the core thickness $(D)$. Therefore, a relatively minor change in one parameter can lead to a significant alteration in the properties of the core. This, in turn, changes the properties of the panel, thus offering flexibility to tailor a material to a specific requirement [28-30].

Hence, with existing production process, it is possible to adjust honeycomb core sandwich composites to achieve superior mechanical properties through varying the core and panel configuration. This, in turn, improves both the strength and stiffness of the sandwich composite-based heliostat structure. However, accurately predicting the heliostat's structural performance based on its honeycomb core's configuration using classical analytical approaches are at best cumbersome and, at worst, unable to facilitate the predictions. Moreover, determining the optimal honeycomb core and panel configuration, among a multitude of possible combinations, that delivers the best trade-off between the panel's weight reduction and structural integrity is not an easy task. The complex nonlinear material behaviour, along with the large number of design variables and performance constraints, is a challenge to traditional deterministic and classical statistical-based design of experiments methods that are generally time-consuming and inefficient with the presence of local optima [31, 32]. This heightens the need for an accurate and powerful prediction-optimization method that overcomes such limitations.

\subsection{Artificial Neural Network (ANN) Modelling}

Given the nonlinearities and challenges to existing techniques, the problem appears well suited to the use of a machine learning technique, such as an artificial neural network (ANN). ANN has emerged as one of the prominent techniques for modelling complex nonlinear relationships, particularly in situations where the development of phenomenological or conventional regression models becomes impractical or cumbersome [33]. ANN is a biologically inspired computational technique that emulates the human brain's behaviour and learning process [34]. This approach does not require explicit knowledge of the physical phenomena under investigation [35] but depends solely on the historic input-output dataset (example set) to learn the relationship between the data through training. ANN-based models provide multiple advantages, including the possession of an outstanding generalization ability owing to which it can accurately predict outputs for a new input data set, and the capability of dealing with noisy data and uncertainties [36].

Owing to their several attractive characteristics, the ANN approach has been extensively used in numerous applications in engineering, medicine, meteorology, economics, psychology and many other fields [34, 35, 37, 38]. In light of this, several studies have explored the use of ANN's to the assessment of sandwich composite panels [39-47]. However, with regard to honeycomb core sandwich composites, there tends to be a scarcity of studies that attempt to establish a generalized prediction model that can capture the influence of each of the honeycomb core's geometrical parameters [cell wall thickness $(t)$, and the cell wall angle $(\varphi)$, cell wall length $(a)$, core thicknesses $(D)]$. The few attempts found in literature [39-42] were limited by the geometrical parameters considered and the variations in the cell geometry.

\subsection{Particle Swarm Optimization (PSO)}

In realizing a lightweight, but stiff, heliostat, there is a need to optimize the materials to achieve this. In recent years, several nature-inspired optimization techniques have come into existence including genetic algorithms (GA) [48], ant colony optimization (ACO) [49], bacterial foraging optimization (BFO) [50], artificial bee colony (ABC) [51] and particle swarm optimization (PSO) [52]. Of these, particle swarm optimization (PSO) is a particularly promising and effective optimization technique for solving highly constrained nonlinear and non-convex optimization problems 
[53]. Introduced by Kennedy and Eberhart [52], the PSO algorithm is based on the cooperative behaviour among species such as bird flocking and fish schooling. The positions of points (particles) in the design space record the potential solutions of an optimization problem. Each particle updates its location according to its own best position and the entire swarm's best position at each generation [54]. PSO has many merits over other optimization techniques, such as the fewer number of parameters to adjust unlike many other competing techniques, the low computational time and the flexibility to combine with other techniques to form hybrid tools. Added also, the PSO algorithm does not depend on the initial solution to start its iteration process $[55,56]$.

Because of its ease of implementation and fast searching speed, the PSO algorithm has been widely used in various engineering applications [54, 56-58] including several studies that utilized PSO in honeycomb sandwich composite investigations [41, 59-63]. However, it is surprising that these studies did not consider all the honeycomb core's physical parameters [core thickness $(D)$, cell wall angle $(\varphi)$, cell wall thickness $(t)$ and the cell wall length $(a)]$ in their optimization problems, considering the impact that each of these parameters has on the performance of honeycomb cores.

\subsection{Overview and Contribution}

Given the recent developments and potential application of machine learning techniques, ANN in particular, it is surprising that their utilization in the design of central tower CSP systems is not more widely discussed in the literature, and to heliostats in particular. Having a predictive model that estimates the heliostat's structural performance under the worst-case operational conditions would eradicate the need to establish a fluid-structure interaction (FSI) model [combined computational fluid dynamics and finite element analysis (CFD-FEA)] for design variations. This, in turn, reduces the implementation time and minimizes unnecessary computations. Furthermore, it appears that the utilization of PSO method for structural optimization of heliostats has not been studied yet. Rather, the use of PSO in central tower CSP systems' has mainly focused on optimizing the heliostat field layout and the aiming strategy only [64-68].

As such, the aim of this work is to utilize artificial neural network (ANN) technique and particle swarm optimization (PSO) algorithm to establish a novel prediction-optimization (ANN-PSO) model that predicts the structural performance of honeycomb sandwich composite-based heliostats, and determines the optimum honeycomb core configuration leading to minimum self-weight of the heliostat's sandwich composite panel while satisfying the necessary performance requirements (i.e. optical and material failure). Such an integrated approach is intended to provide a useful, flexible and time-efficient tool for heliostat designers to optimize and tailor the structural performance of honeycomb sandwich composite-based heliostats (i.e. the chosen site's maximum design wind velocity and optical and material failure limits).

\section{Materials and Methods}

\subsection{Structural Configuration of the Honeycomb Sandwich Composite-Based Heliostat}

As the aim of the work was to explore the use of honeycomb composites as heliostats for CSP, it was necessary to ensure a comparable context to existing work in the field. In this respect, Sandia National Laboratories' analysis of heliostat cost versus size [6] indicated that heliostats of around 150 $\mathrm{m}^{2}$ show the best economy. Hence, for this study, a honeycomb sandwich composite-based heliostat structure, schematically shown in Fig. 1, formed the basis of this analysis. The heliostat consists of a $148 \mathrm{~m}^{2}[11.84 \mathrm{~m}(H) \times 12.5 \mathrm{~m}$ $(W)]$ rectangular sandwich composite plate supported by four steel attachments (Young's modulus $(E)=200 \mathrm{GPa}$; Poisson's ratio $(v)=0.3$; shear modulus $(G)=76.92 \mathrm{GPa}$; density $\left.(\rho)=7850 \mathrm{~kg} / \mathrm{m}^{3}\right)$, each approximately $6 \mathrm{~m}$ long and $0.15 \mathrm{~m}$ wide. Unlike existing large-area steel-based heliostats, such as the ATS heliostat [6, 7], where steel-based trusses extend along the entire reflector, the attachments were made smaller to reduce the amount of steel, with the sandwich panel providing the mirror module with the necessary rigidity and support. Both the panel and the attachments are mounted on a steel-based torque tube/pedestal configuration in what is known as a T-type configuration (the torque tube and the pedestal together form a ' $\mathrm{T}$ ' and are coupled to each other by the drive system). This configuration was selected because state-of-the-art central tower CSP plants typically use T-type heliostats with azimuth-elevation tracking mechanisms $[8,69]$.

Focusing on the sandwich composite panel, it was assumed to be an aluminium honeycomb core sandwiched between two $0.3 \mathrm{~mm}$ aluminium skins. Aluminium $(E=69$ $\mathrm{GPa} ; v=0.33 ; G=27 \mathrm{GPa} ; \rho=2700 \mathrm{~kg} / \mathrm{m}^{3}$ ) is often used for constructing honeycomb sandwich panels [70], due to its comparatively low-cost, high strength-to-weight ratio, corrosion-resistance and good energy-absorbing capabilities [23, 25].

Furthermore, a 4-mm-thick glass mirror, similar to the one used in the ATS heliostat, is mounted on the top surface of the sandwich composite. Mirrored glass $(E=68.94 \mathrm{GPa}$; $v=0.23 ; G=28.02 \mathrm{GPa} ; \rho=2457.6 \mathrm{~kg} / \mathrm{m}^{3}$ ) was selected as the reflective surface, being relatively inexpensive, with a high reflectance (0.93-0.94) and durability (20-25 years' lifespan), and is widely accepted by the industry $[8,69]$. To accommodate differences in thermal expansion between the glass facets and the metallic support structure, mirrors are 
Fig. 1 Sandwich compositebased heliostat structure

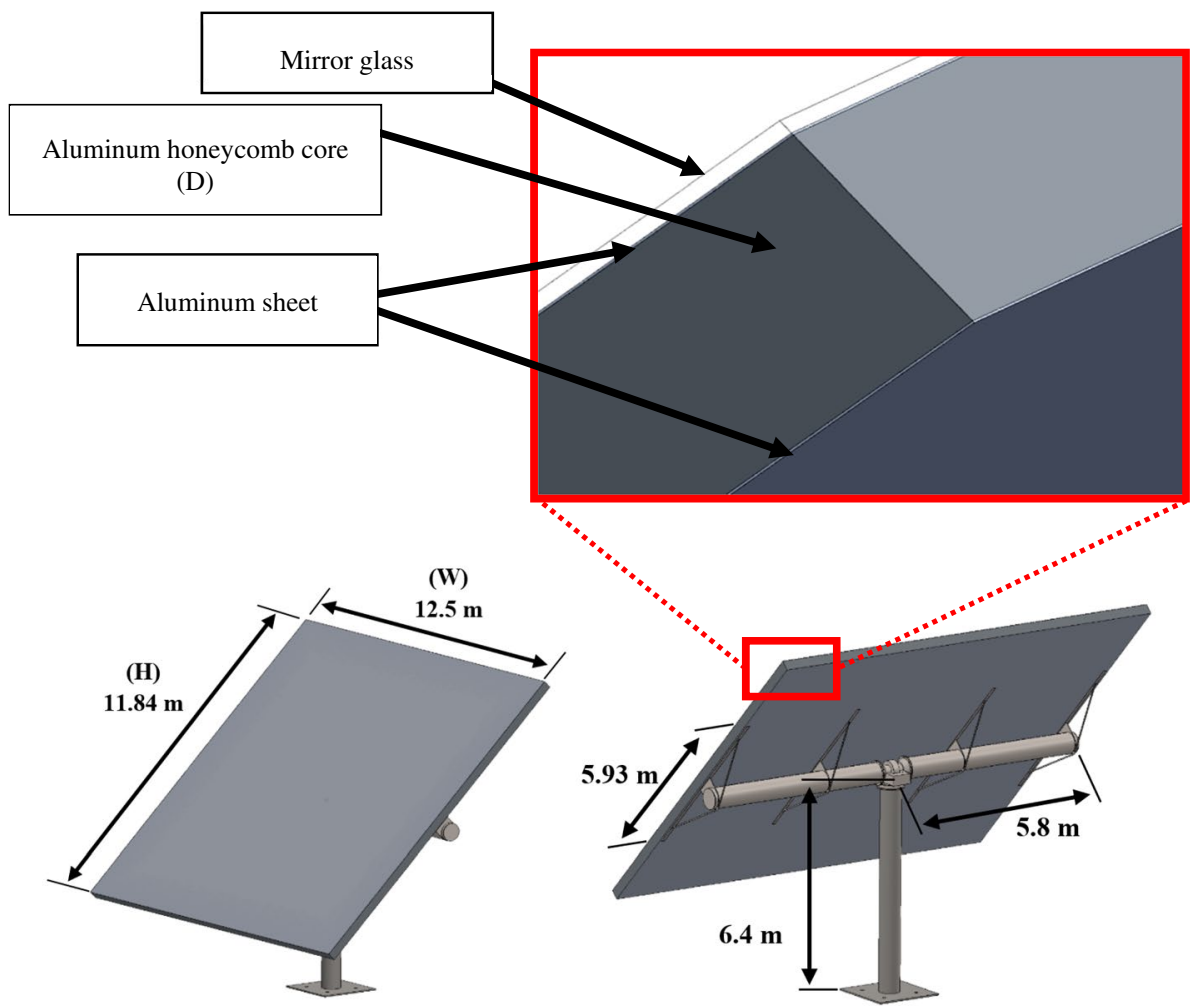

often connected to the support structure via flexible adhesives $[8,71]$. However, for model simplification, the inclusion of this layer was neglected.

\subsection{Design of the Artificial Neural Network Model}

In developing the ANN model, there were five key input variables, the first four being the honeycomb core's physical parameters [core thickness $(D)$, cell wall angle $(\varphi)$, cell wall thickness $(t)$ and the cell wall length $(a)$ ] and the final being the wind speed. Now, according to [27], the severest operational condition exists at a tilt angle of $30^{\circ}$ when the wind flow is onto the mirrored heliostat surface. Therefore, taking the worst-case condition as a baseline, a dataset was developed using the validated FSI model discussed in [27] for three different core thicknesses $(D) ; 150,300$ and $450 \mathrm{~mm}$. For each of these core thicknesses, the following variations in the honeycomb cell geometry were considered: cell wall thicknesses $(t)$ between 0.02 and $0.05 \mathrm{~mm}$, cell wall lengths $(a)$ ranging from 5 to $10 \mathrm{~mm}$ and cell wall angles $(\varphi)$ varying between $10^{\circ}$ and $50^{\circ}$, as shown in Fig. 2. Moreover, the wind speed was varied from 5 to $20 \mathrm{~m} / \mathrm{s}$ to have a better generalized model that considers the desired site's maximum recorded wind speed, delivering a total of 1440 data points.

Given this, Fig. 3 provides a schematic representation of the proposed network with the defined inputs and outputs, where the ANN model's output variables represent the heliostat's structural performance parameters. These parameters include the weight saving relative to the existing $1550 \mathrm{~kg}$ ATS heliostat described previously [6] (determined by Eq. 1), the mirror surface's maximum displacement, the maximum recorded stress at the heliostat panel's lower aluminium sheet and a 'core crush index'. This core crush index is defined as the ratio of the calculated critical collapse strength of the honeycomb core $\left(\sigma_{\text {collapse }}\right)$ at a specific cellular configuration relative to the maximum recorded stress at the core (Eq. 2) and a value greater than 1 indicates that the core is unlikely to experience material failure due to cell wall buckling.

Weight reduction percentage $(\%)=\frac{\left(W_{\mathrm{ATS}}-W_{\mathrm{hsch}}\right)}{W_{\mathrm{ATS}}} \times 100$

where $W_{\mathrm{ATS}}$ is the total weight of the ATS heliostat's mirror support structure; $W_{\mathrm{hsch}}$ is the total weight of the honeycomb sandwich composite-based heliostat's panel at a specific honeycomb core configuration.

\section{Core crush index}

$=\frac{\text { Critical collapse strength of honeycomb }\left(\sigma_{\text {collapse }}\right)}{\text { Maximum recorded stress at the honeycmb core }}$

Now in ANNs, the network learns the relationship between the data in the input and output layers using a training process that consists of several steps depending on 


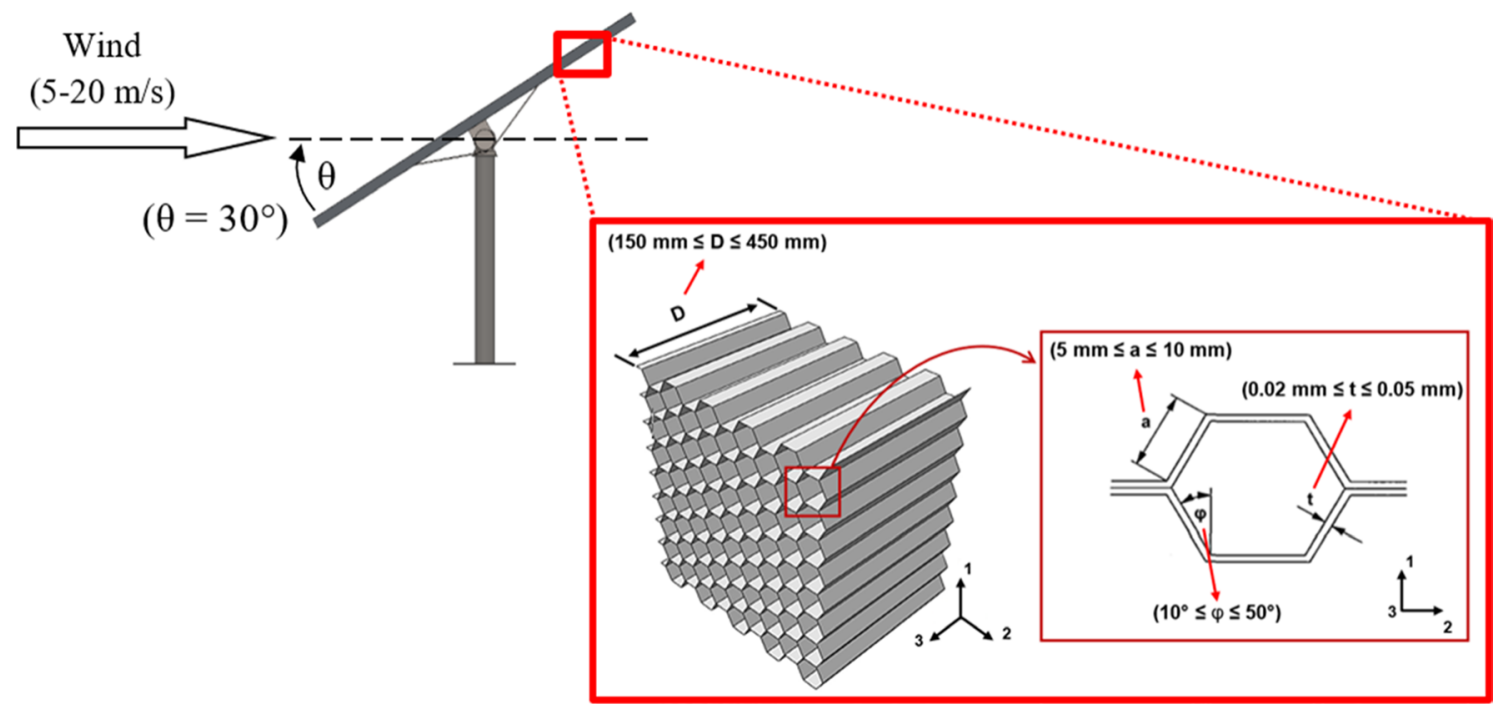

Fig. 2 Configurations used for the network design input dataset and design variables of optimization study with their search ranges

Fig. 3 Inputs and outputs of the ANN model for the prediction of the structural performance of the honeycomb sandwich composite-based heliostat

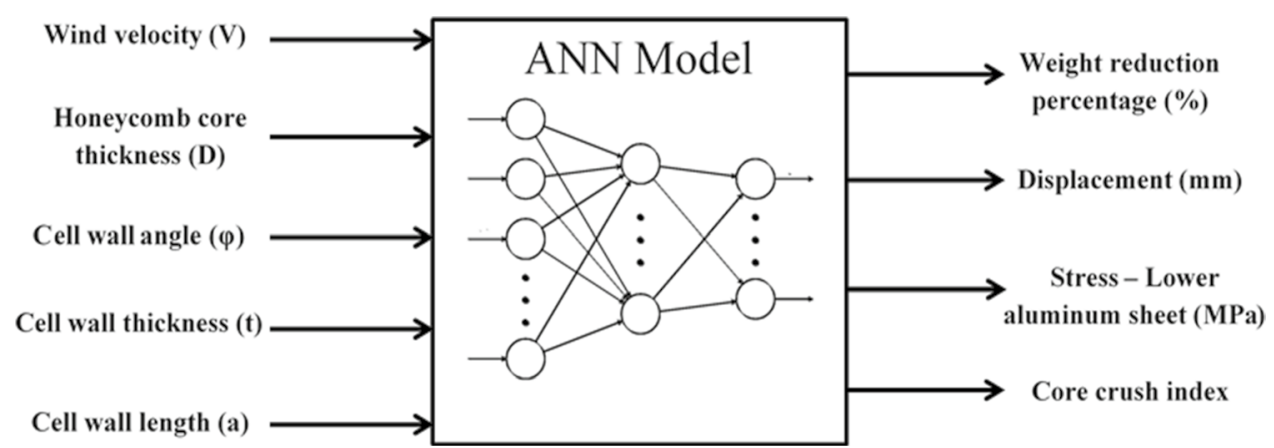

the utilized training algorithm. In this work, two training algorithms were explored, the Levenberg-Marquardt (LM) and Bayesian Regularization (BR). When utilizing the LM algorithm, the training occurs through three phases: training, validation and testing. As such, the input data was randomly divided into three sets: $70 \%$ for training, $15 \%$ for testing and $15 \%$ for validation. However, the BR training algorithm only uses two phases: training and testing [72]. Hence, for this algorithm, the input data were randomly divided with $70 \%$ of the data used for training and 30\% used for testing.

In developing an ANN, the number of hidden neurons is a tuneable parameter, which is normally unknown and determined by the desired ANN model's performance and complexity. For instance, having too few neurons in the hidden layer can give rise to lower predictive accuracy (i.e. the nonlinear trends in the dataset cannot be captured by the network). On the other hand, having too many neurons in the hidden layer can result in problems such as overfitting and high computational time [34]. Therefore, a trade-off needs to be found in order to determine the number of neurons in the hidden layer that provides the best prediction performance.
In this study, the number of neurons in the hidden layer was varied between 3 and 101 neurons and assessing the model's performance for each set of neurons using the tansig and logsig transfer functions.

The most common way to evaluate the performance of an established ANN model is by calculating the mean square error (MSE) (Eq. 3) and the determination coefficient $\left(R^{2}\right)$ between the model predicted output and actual values (Eq. 4). When the MSE is at its minimum and $R^{2}$ is high, $R^{2}>0.98 \sim 0.99$, a model can be judged to be providing good predictive capabilities, and so were used as the metrics in this study.

$$
\begin{aligned}
& \text { MSE }=\frac{1}{n} \sum_{i=1}^{n}\left(Y_{\text {act }, i}-Y_{\text {pred }, i}\right)^{2} \\
& R^{2}=1-\frac{\sum_{i=1}^{n}\left(Y_{\text {act }, i}-Y_{\text {pred }, i}\right)^{2}}{\sum_{i=1}^{n}\left(Y_{\text {act }, i}-Y_{\text {avg }}\right)^{2}}
\end{aligned}
$$


where $n$ is the number of data points, $Y_{\text {act }}$ is the cell wall length, $Y_{\text {pred }}$ is the predicted value from the established network, and $Y_{\text {avg }}$ is the mean of the $Y_{\text {act }}$ values.

On this basis, the method for establishing the ANN model is shown schematically in Fig. 4.

\subsection{Particle Swarm-Based Structural Optimization of the Honeycomb Sandwich Composite-Based Heliostat}

Having defined the ANN, it was necessary to implement the particle swarm optimization (PSO) to optimize the properties of the heliostat material. In this regard, the PSO algorithm emulates the cooperative behaviour among species such as flocks of birds and schools of fishes. Hence, potential solutions of an optimization problem are regarded as points (particles) in the design space. Each particle ( $i$ )

Fig. 4 Flowchart of the proposed ANN methodology

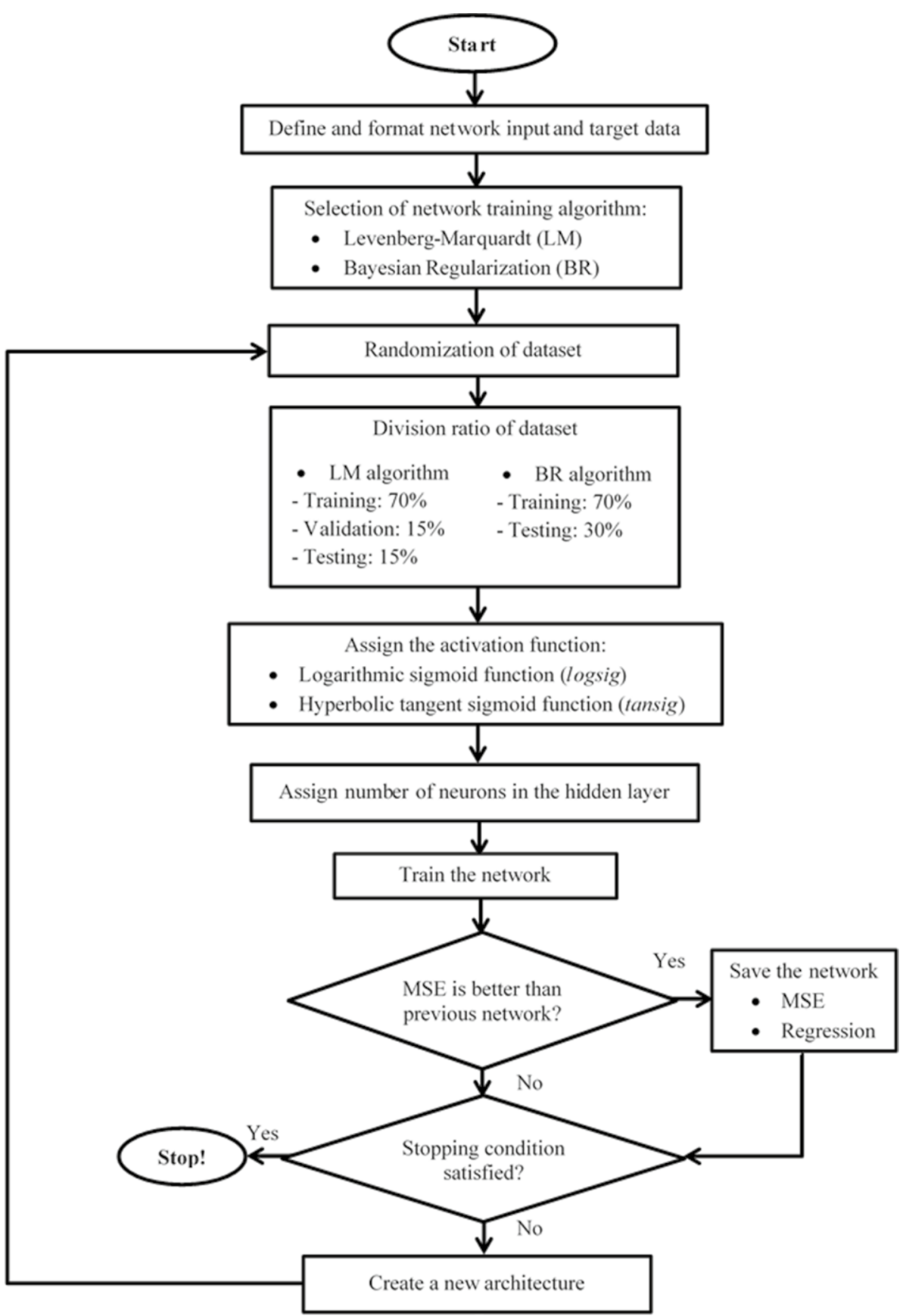


possesses two characteristic components: position $\left(x^{i}\right)$ and velocity $\left(v^{i}\right)$. The particle's position is the candidate solution, whereas the velocity determines the updating direction of the particle. These particles in the swarm proceed through the feasible solution space to explore optimal solutions. Each particle updates its location according to its own best position $\left(\right.$ pbest $_{k}{ }^{i}$ ) and the entire swarm's best position $\left(\right.$ gbest $\left._{k}\right)$ at each generation (iteration) $(k)$. The velocity and position of a particle are updated based on Eqs. 5 and 6.

$v_{k+1}^{i}=\omega v_{k}^{i}+c_{1} \operatorname{rand}_{1}\left(\operatorname{pbest}_{k}^{i}-x_{k}^{i}\right)+c_{2} \operatorname{rand}_{2}\left(\operatorname{gbest}_{k}-x_{k}^{i}\right)$

$x_{k+1}^{i}=x_{k}^{i}+v_{k+1}^{i}$

where $v_{k}^{i}$ and $x_{k}^{i}$ are the velocity and position of the $i$ th particle in $k$ th generation, respectively. $c_{1}$ and $c_{2}$ are acceleration constants (defined by $c_{1}+c_{2}>4$ [31]) which determine the cognitive and the social learning rates, respectively, $\omega$ is an inertia weight used to improve the convergence speed, and $\operatorname{rand}_{1}$ and rand $_{2}$ are two random numbers comprise within the range of 0 and 1 .

For selecting the values of the acceleration constants $c_{1}$ (cognitive learning parameter) and $c_{2}$ (social scaling parameter), it was assumed that the cognitive behaviour of each particle cannot be privileged compared to the social (collective) behaviour. Hence, no difference can be made between the two constants $c_{1}$ and $c_{2}$. In this study and based on the restriction: $c_{1}+c_{2}>4$ [31], a value of $c_{1}=c_{2}=$ 2.05 was selected. In determining the inertia weight $(\omega)$, the best suggested approach is by having a dynamic inertia weight (Eq. 7) according to the number of iterations [31, 56]. At the start of the search procedure, each particle must be more flexible with respect to the group's global tendency. As the search procedure converges to the optimal solution, this flexibility must be reduced progressively. In this regard, it is crucial to have a varying $\omega$ to achieve the best swarm performance.

$\omega($ iter $)=\frac{\left(\text { iter }_{\max }-\text { iter }\right)}{\text { iter }_{\max }} \times\left(\omega_{\text {max }}-\omega_{\min }\right)+\omega_{\text {min }}$

where iter represents the current generation, iter $_{\max }$ is the maximum generation number, and $\omega_{\max }$ and $\omega_{\min }$ are, respectively, the maximum and minimum values of the inertia weight, which can be set as 0.9 and 0.4 , respectively, as suggested by previous PSO investigations [31, 58, 73].

\subsubsection{Optimization Problem Formulation (Objective Function, Decision Variables and Constraints)}

Now for this study, the main objective function is the total weight of the heliostat's sandwich composite panel, which is intended to be as light as possible and ideally lighter than the existing $148 \mathrm{~m}^{2}$ steel-based ATS heliostat's mirror support structure (approximately $1550 \mathrm{~kg}$ [6]). Hence, the objective function can be formulated as shown in Eq. 8:

Maximizeweight reduction percentage (\%)

$$
=\operatorname{Maximize} \frac{\left(W_{\mathrm{ATS}}-W_{\mathrm{hsch}}\right)}{W_{\mathrm{ATS}}} \times 100
$$

The optimization procedure consists of searching for the various geometrical parameters of the sandwich compositebased heliostat's panel. Therefore, the honeycomb core's physical parameters [core thickness $(D)$, cell wall angle $(\varphi)$, cell wall thickness $(t)$ and the cell wall length $(a)$ ] were defined as design variables, as illustrated in Fig. 2. The wind velocity, on the other hand, was not defined as a design variable and was considered a flexible input parameter that is set by the user, depending on the requirements associated with the desired site's maximum recorded wind speed.

In order to accomplish the investigation objective, which is to determine the optimum honeycomb core configuration leading to minimum self-weight, the heliostat structure must satisfy restrictive requirements (constraints) concerning optical, material failure and weight criterions. For the optical criteria, the structure should be able to keep its deformation below $21.3 \mathrm{~mm}$ (using Björkman's [74] approach to calculate the maximum allowable displacement). As for the material failure criterions, the two highly stressed components of the sandwich panel that have a higher probability of experiencing material failure are the lower aluminium sheet and the aluminium honeycomb core.

For the lower aluminium sheet, the stresses imposed upon it should not exceed the yield strength of the material $\left(\sigma_{y}=\right.$ $280 \mathrm{MPa}$ ) so that the face yielding failure mode does not occur. For the honeycomb core, the ratio of the calculated critical collapse strength of the honeycomb core at a specific cellular configuration relative to the maximum recorded stress at the core (defined earlier as core crush index) should be greater than 1. It is important to highlight that these requirements are the minimum conditions necessary for a reliable operation of a heliostat, though constraints can be altered for an enhanced structural performance depending on the heliostat designer's needs.

\subsubsection{ANN-PSO Optimization Procedure}

Having established both the ANN and PSO, Fig. 5 illustrates the relationship between the models and provides a flowchart of the combined algorithm. From this, it can be seen that the ANN-PSO approach involves the following major steps: (1) set the PSO parameters' values (e.g. number of particles, maximum number of iterations, etc.) and initialize randomly the swarm particles' position and velocity 


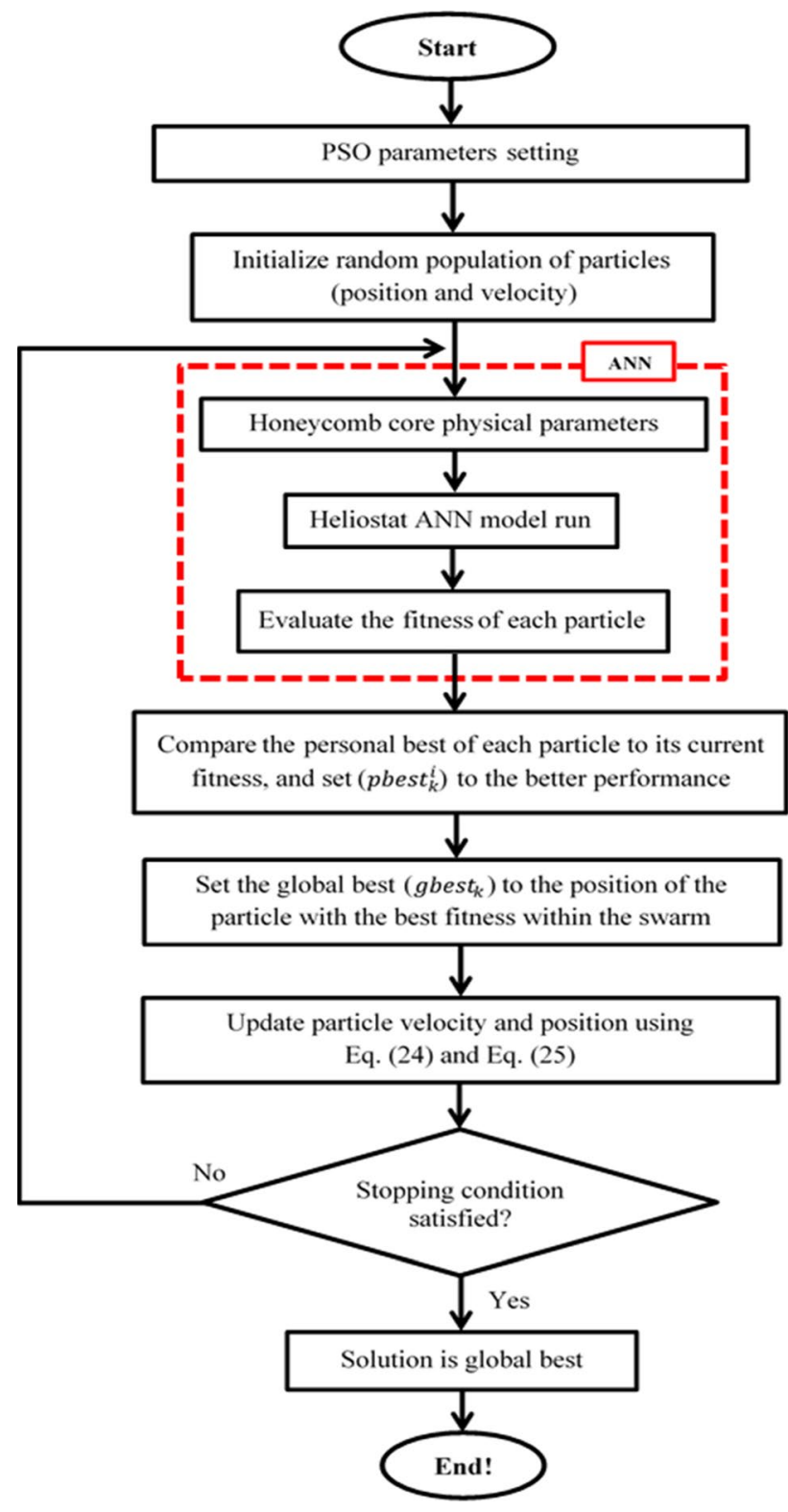

Fig. 5 Flowchart of the ANN-PSO methodology in the population; (2) evaluate each particle's fitness, using an objective function as outputs from the ANN model run with inputs of the honeycomb core's physical parameters (i.e. values of particles' position); (3) update and record the local best ( pbest $_{k}^{i}$ ) and the global best $\left(\right.$ gbest $_{k}$ ) values while comparing the currently calculated fitness values with the previous records; (4) update the velocity and position of each swarm particle using Eqs. (5) and (6), respectively; (5) check the stopping criteria, so that the optimization process can be repeated until the desired value of the objective function is reached with an accepted deviation or unchanged or the number of iterations reaches the predefined maximum number of iterations (iter ${ }_{\max }$ ). As the PSO algorithm arrives at the imposed termination criteria, the final recorded global best position over all iterations leads to the optimization problem's solution.

In undertaking the optimization process, the swarm size (number of particles) was varied from 5 to 60 particles. The number of particles is an adjustable parameter of which is normally unknown and determined by the algorithm's convergence performance and processing time. For small numbers of particles, the swarm will fall effortlessly into local optima without being able to leave later to find better results. On the other hand, having too many particles might result in better convergence towards a more global optimum (particles gather more information to have a further global view regarding the search space) but will result in high computational time. In this regard, the swarm size was varied to analyse and find the suitable number of particles that delivers the best performance for convergence and processing time. Moreover, the number of iterations was set sufficiently high (iter $_{\max }=100$ ) to ensure a good convergence to the optimum solution with no or very little improvement.

To demonstrate the feasibility of the proposed approach for this system, two scenarios were considered and are summarized in Table 1. In the first case, the design requirements are the minimum conditions necessary for a reliable operation of a heliostat. However in the second case, it was

Table 1 Description of the three cases to be optimized

\begin{tabular}{|c|c|c|c|}
\hline & Configuration 1 & Configuration 2 & Configuration 3 \\
\hline Chosen site's maximum design wind velocity $(\mathrm{m} / \mathrm{s})$ & 20 & 20 & 5 \\
\hline \multicolumn{4}{|l|}{ Design variables } \\
\hline Core thickness $(D)(\mathrm{mm})$ & To be optimized & To be optimized & To be optimized \\
\hline Cell wall angle $(\varphi)$ (degree) & To be optimized & To be optimized & To be optimized \\
\hline Cell wall thickness $(t)(\mathrm{mm})$ & To be optimized & To be optimized & To be optimized \\
\hline Cell wall length (a) (mm) & To be optimized & To be optimized & To be optimized \\
\hline \multicolumn{4}{|l|}{ Design requirements } \\
\hline Maximum allowable structural deformation (mm) & 21.3 & 10 & 21.3 \\
\hline Maximum allowable stress at lower aluminium sheet (MPa) & 280 & 100 & 280 \\
\hline Minimum allowable core crush index & 1 & 5 & 1 \\
\hline
\end{tabular}


assumed that the targeted heliostat was subjected to a wind of $20 \mathrm{~m} / \mathrm{s}$, but the design requirements were altered for more enhanced structural performance. As for the third case, the design wind speed was reduced to $5 \mathrm{~m} / \mathrm{s}$, with minimum design requirements similar to the first case.

\section{Results and Discussion}

\subsection{Effect of the Geometric Configuration of Honeycomb on the Aero-Structural behaviour Characteristics of the Sandwich Composite-Based Heliostat}

Prior to implementing an ANN-PSO model, there is a need to understand the impact that each of the honeycomb's geometric properties [i.e. cell wall angle $(\varphi)$, cell wall length $(a)$, cell wall thickness $(t)]$ has on the heliostat structure. To this end, it was decided to perform a parametric analysis of how each geometric property could potentially affect the structural behaviour characteristics of the heliostat's sandwich composite panel, and the desired weight savings.

Exploring the effect of cell wall length (a), Fig. 6 shows the displacement distribution of the heliostat's reflective surface and stress distribution at both the lower aluminium sheet and the aluminium honeycomb core, for a core with a thickness $(D)$ of $300 \mathrm{~mm}$, cell wall thickness $(t)$ of $0.02 \mathrm{~mm}$ and cell wall angle $(\varphi)$ of $10^{\circ}$, as the honeycomb's cell wall length is varied. It can be seen that increasing the honeycomb's cell wall length was found to strongly affects the panel's stiffness, causing the heliostat's lower edge deflection to increase until it reaches its maximum at this configuration when the cell wall length approaches $a=10 \mathrm{~mm}$. Similarly, and corresponding to the variation in the heliostat's structural deformation caused by changing the cell wall length, the same trend was observed in the stress concentrations at both the lower aluminium sheet and the honeycomb core (Fig. 6). This is due to the fact that as the honeycomb's cell wall length increases; the honeycomb cells become less dense, and the area fraction of non-load-carrying cell walls increases. This results in a reduction in the Young's modulus of the honeycomb core in all directions $\left(E_{1}, E_{2}, E_{3}\right)$, causing the heliostat panel to be less stiff and less resistant to external loads. This could lead to a reduction in the panel's ability to meet the other performance constraints placed on it. The same observation was also identified in Ivañez et al.'s [30] work, where they investigated both numerically and experimentally the effect of the variation of cell wall length $(a)$ on the crushing behaviour and on the energyabsorption capacity of honeycomb cores. In their work, it

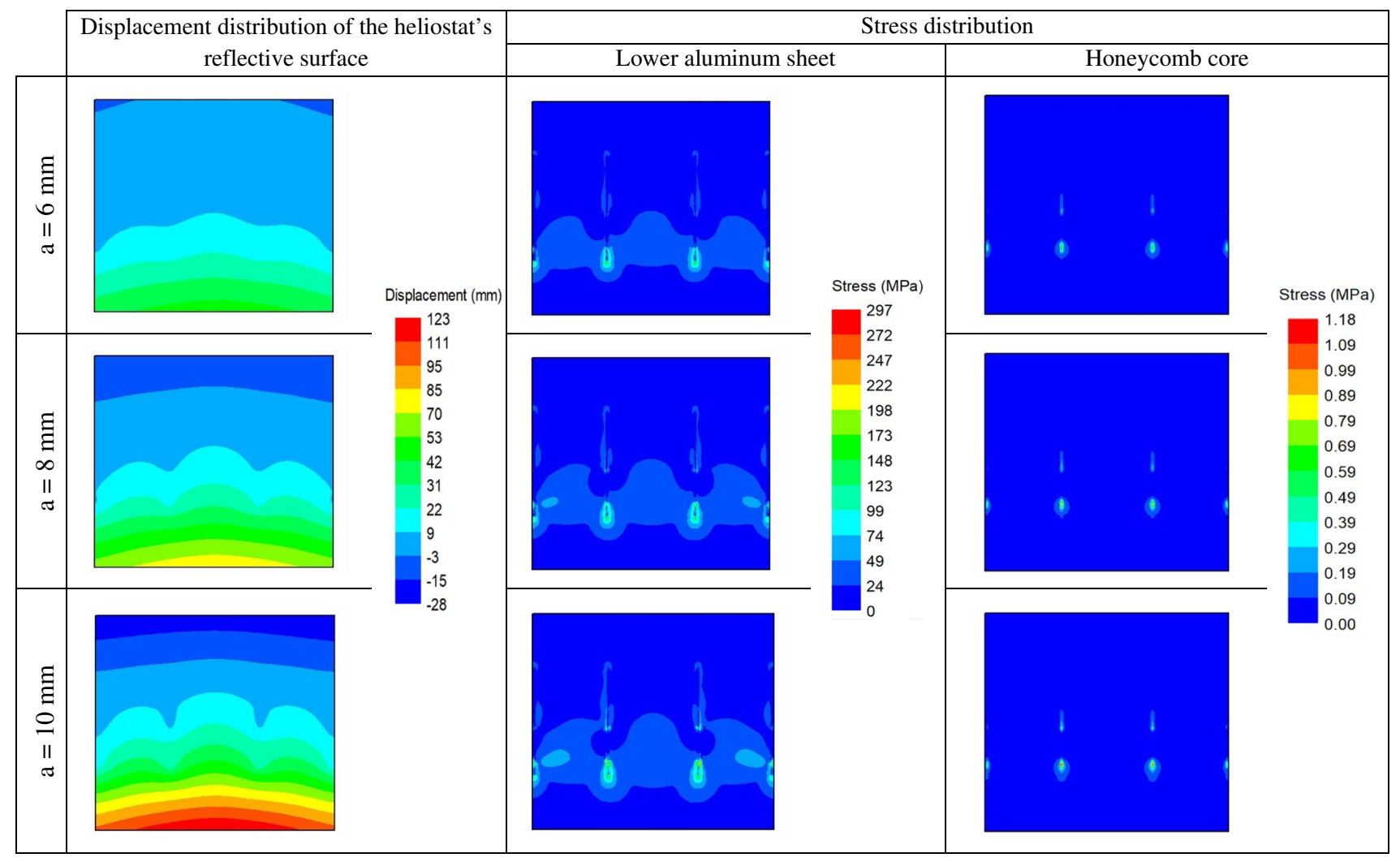

Fig. 6 Displacement and stress distribution results for different cell wall lengths $(a)$ 


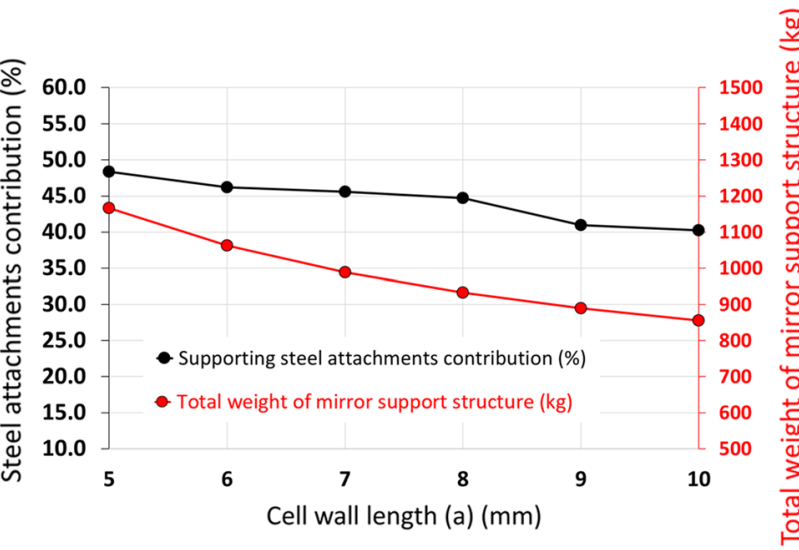

Fig. 7 Cell wall length $(a)$ effect on the mirror support structure's attainable weight reduction was found that specimens with large cells had lower energyabsorption levels as the contact area for bearing the compressive load was smaller, leading to a lower average crush force. Although this appears undesirable, weight savings can be achieved by increasing the cell wall length, as shown in Fig. 7. This reduced weight on the supporting structure results in a decrease in the supporting steel attachments' deformation contribution to the total deformation experienced by the heliostat.

As for the cell wall thickness ( $t$ ) effect on the structural behaviour characteristics of the heliostat's sandwich composite panel, Fig. 8 shows the displacement distribution of the heliostat's reflective surface and the stress distribution at both the lower aluminium sheet and the aluminium honeycomb core for a core with a thickness $(D)$ of $300 \mathrm{~mm}$, cell wall length $(a)$ of $10 \mathrm{~mm}$ and cell wall angle $(\varphi)$ of $40^{\circ}$. From the results, it can be seen that increasing the honeycomb's cell wall thickness $(t)$ causes a decrease in

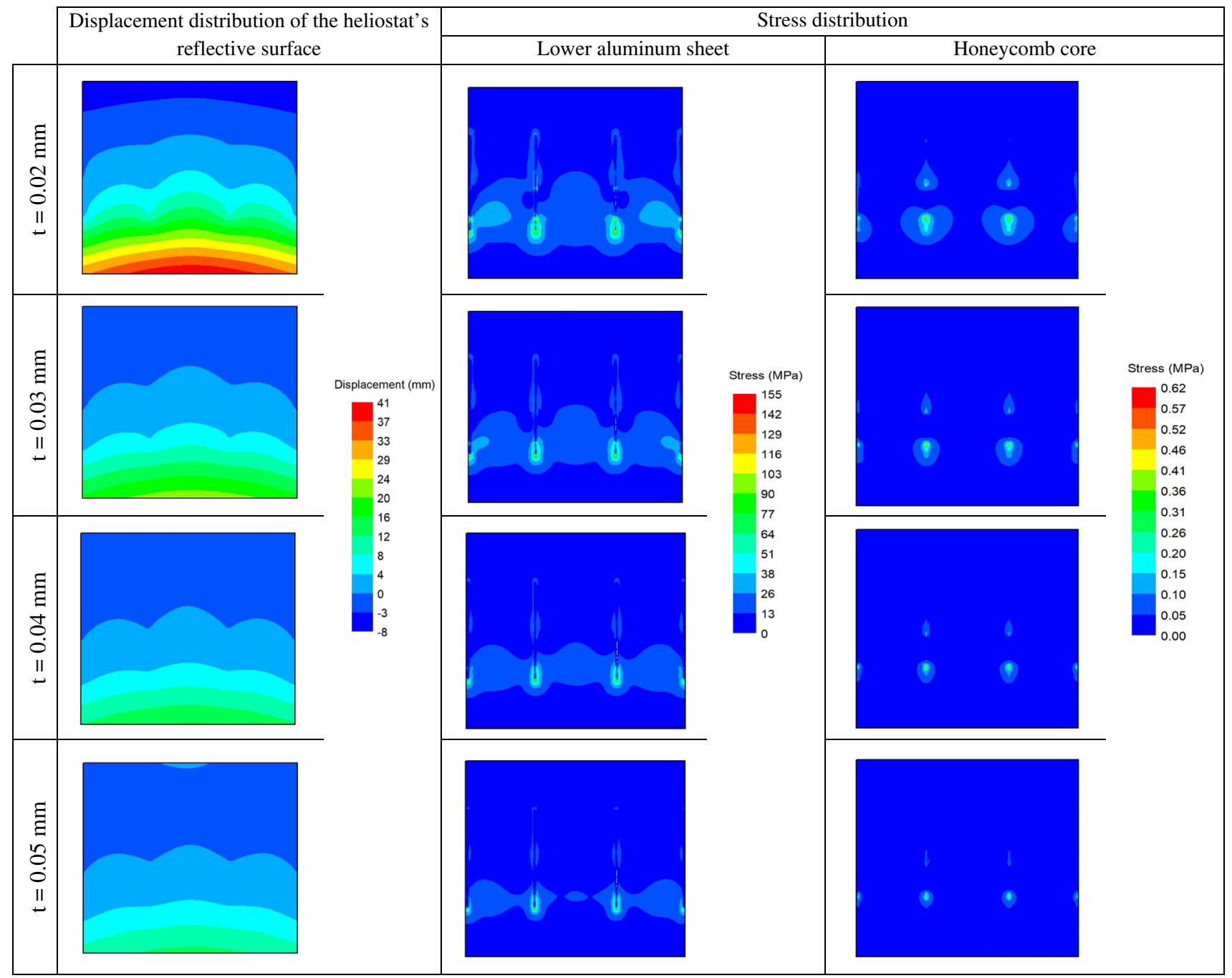

Fig. 8 Displacement and stress distribution results for different cell wall thicknesses $(t)$ 
the structural deflection of the panel's lower edge region, resulting in lower stresses at the lower ends of the interface between the steel attachments and the panel's back surface. This can be attributed to the fact that, as the honeycomb's cell walls are thickened, their bending resistance increases,

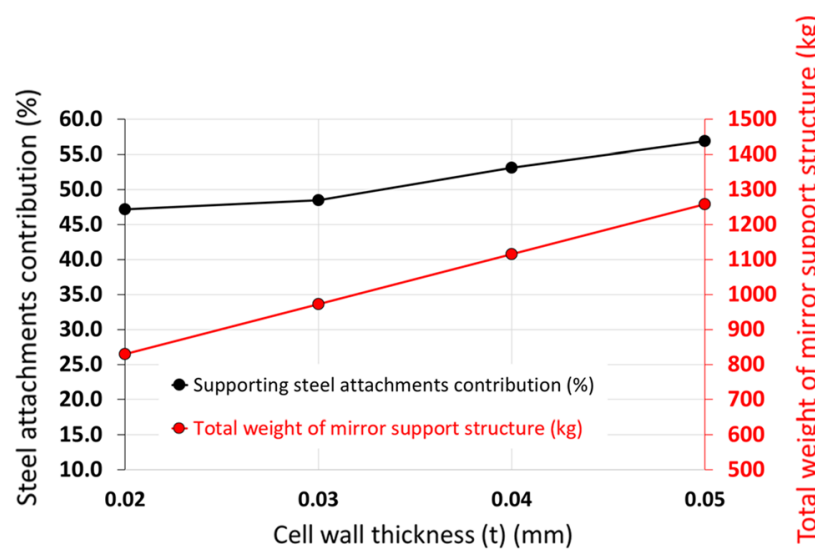

Fig. 9 Cell wall thickness $(t)$ effect on the mirror support structure's attainable weight reduction and consequently, the honeycomb core becomes more resistant to local buckling and crushing, causing an increase in the heliostat panel's stiffness and resistance to wind loads. Referring to Ivañez et al.'s [30] work that addressed, along with other parameters, the impact of cell wall thickness $(t)$ on the performance of honeycomb cores, their investigation highlighted that cell wall thickness is the parameter that most affected the results, reaching compressive load values of up to 3.5 times higher with the doubled cell-wall thickness model. Though this appears desirable, increasing the cell wall thickness results in a marked rise in weight (Fig. 9). The substantial increase in the overall weight of the honeycomb core with the increase in cell wall thickness causes the supporting steel attachments to act upon this increase to maintain the deformations of the heliostat.

As for the cell wall angle effect $(\varphi)$, Fig. 10 shows the displacement distribution of the heliostat's reflective surface, and the stress distribution at both the lower aluminium sheet and the aluminium honeycomb core for a core with a thickness $(D)$ of $300 \mathrm{~mm}$, cell wall thickness $(t)$ of $0.02 \mathrm{~mm}$ and cell wall length $(a)$ of $5 \mathrm{~mm}$. It can be seen that the heliostat sandwich panel that consists of a honeycomb core

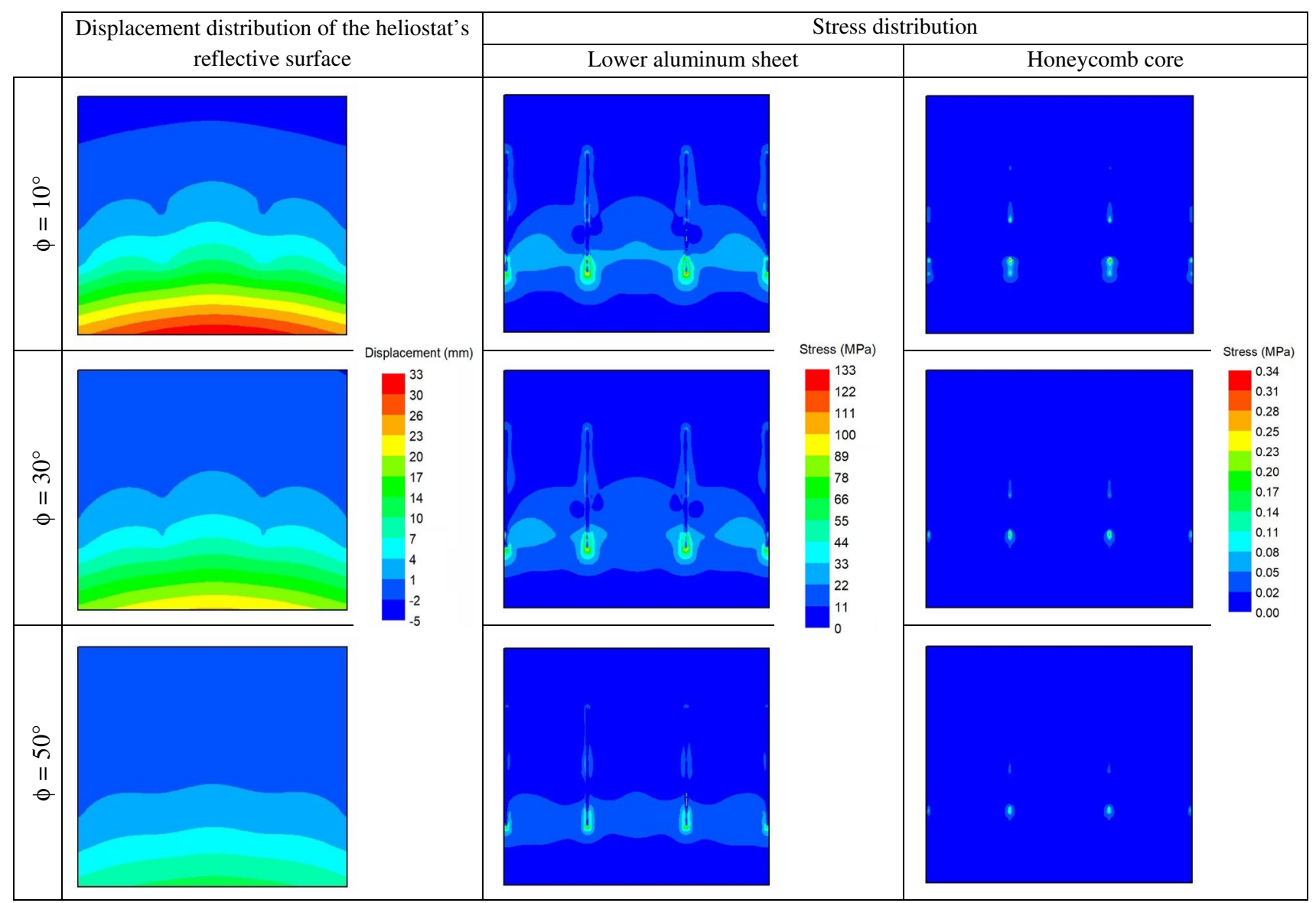

Fig. 10 Displacement and stress distribution results for different cell wall angles $(\varphi)$ 
with cell wall angle $(\varphi)$ of $10^{\circ}$ experiences the maximum structural deformation. Increasing the honeycomb's cell wall angle strongly influences the stiffness of the panel, causing the deflection at the heliostat's lower edge to decrease until it reaches its minimum when the cell wall angle reaches $\varphi=50^{\circ}$. Similarly, and corresponding to the change in the heliostat's structural deformation caused by altering the cell wall angle, the same trend of decrease was seen also in the stress concentrations at both the lower aluminium sheet and the honeycomb core (Fig. 10). This can be attributed to the fact that as the honeycomb's cell wall angle increases; the honeycomb's cell walls become more compact and internally coherent, increasing the area fraction of load-carrying cell walls causes the heliostat panel to be stiffer and more resistant to buckling and crushing. This coincides very well with the findings of Yamashita and Gotoh [29], where they investigated the out-of-plane (normal to the surface) mechanical properties of honeycomb structures with changed cell wall angles. In their study, it was shown that varying the cell structures by this simple method can enhance the honeycomb's out-of-plane crushing strength to almost 1.5 times comparing to the regular hexagonal honeycomb. Despite this observation, it can be clearly noted that for very low cell wall angles $\left(\varphi=10^{\circ}\right)$, the overall weight of the sandwich panel is high. However, with the increase in cell wall angle the overall weight decreases as a result of the increase in the void between the cell walls. Due to the reduced weight on the supporting structure, the contribution of the supporting steel attachments to the total displacement experienced by the heliostat also decreases with a similar trend and reaches its lowest value at $\varphi=30^{\circ}$. Increasing the cell wall angle further, and as described previously that the honeycomb's cell walls become more compact and dense and internally coherent with the increase in cell wall angle, the sandwich panel's overall weight increases. This results in an increase in the supporting steel attachments' deformation contribution to the total deformation experienced by the heliostat (Fig. 11). Despite the appearance of an optima at an angle of $30^{\circ}$ for this case, it needs to be considered that the weight at this point is much larger than those seen in the preceding cases. As such, this point is a local optima, and thus highlights the need for a more advanced optimization strategy such as the ANN-PSO.

\subsection{Assessment and Validation of the ANN Model}

Having shown the impact of the honeycomb's geometric configuration on the aero-structural behaviour characteristics of the sandwich composite-based heliostat, the potential weight savings that could be achieved through variations to the heliostat core's geometric configuration, as well as having noted the shortcomings of a heuristic approach to this

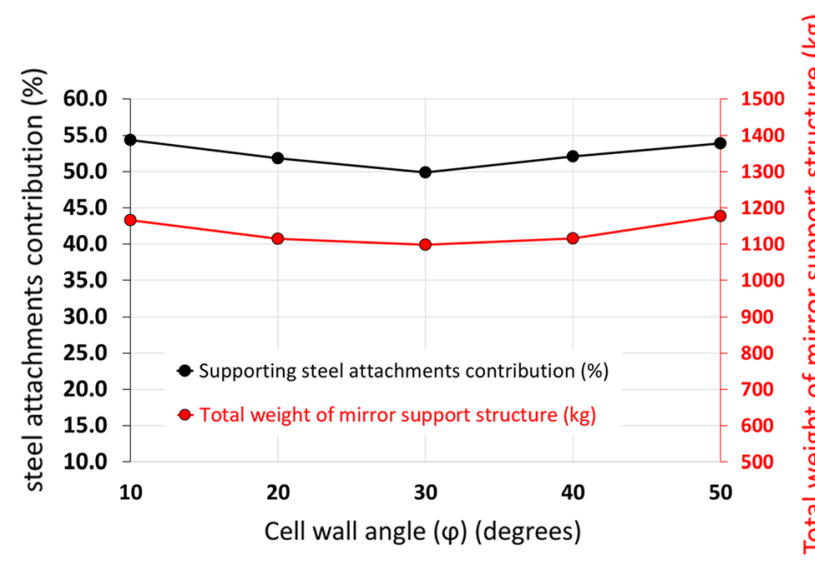

Fig. 11 Cell wall angle $(\varphi)$ effect on the mirror support structure's attainable weight reduction

analysis, attention was turned towards establishing an ANN model and assessing its performance.

As noted previously, two variations were explored, the Levenberg-Marquardt (LM)- and the Bayesian regularization (BR)-based ANN models, trained using the tansig and logsig transfer functions. Figure 12 shows the mean square error (MSE) and determination coefficient $\left(R^{2}\right)$ for both networks, with various number of neurons in the hidden layers. The results demonstrate the number of neurons in the hidden layer does not automatically imply that the ANN model will have a better predictive accuracy. Rather, the best architecture for the ANN model is recognized as that which has a minimum MSE and maximum $R^{2}$. In this regard, the BR training algorithm outperformed the LM algorithm, resulting in lower MSE and higher $\mathrm{R}^{2}$ values. The same remark was also highlighted in Khalid et al.'s [72] work, where their research focused on proposing a procedure to estimate the duration of software projects utilizing ANN. In their work, BR and LM training algorithms were used to train the ANN model. After comparing the performances of the two approaches, it was concluded that BR offers superior results than LM. Furthermore, it is evident that a BR-based ANN model trained using the tansig transfer function showed the best predictions.

Based on these findings, the final network model was trained using the BR algorithm and the tansig transfer function. It constituted of 5 neurons in the input layer, 89 neurons in the hidden layer and 4 neurons in the output layer, as these had shown the minimum MSE and maximum $\mathrm{R}^{2}$ value.

Exploring this further, Fig. 13 shows a normalized comparison between the predicted values from the ANN model and the actual values for the entire dataset. From the results, it can be seen that the optimum model shows good prediction ability, thereby improving our confidence in utilizing it in further analyses. 


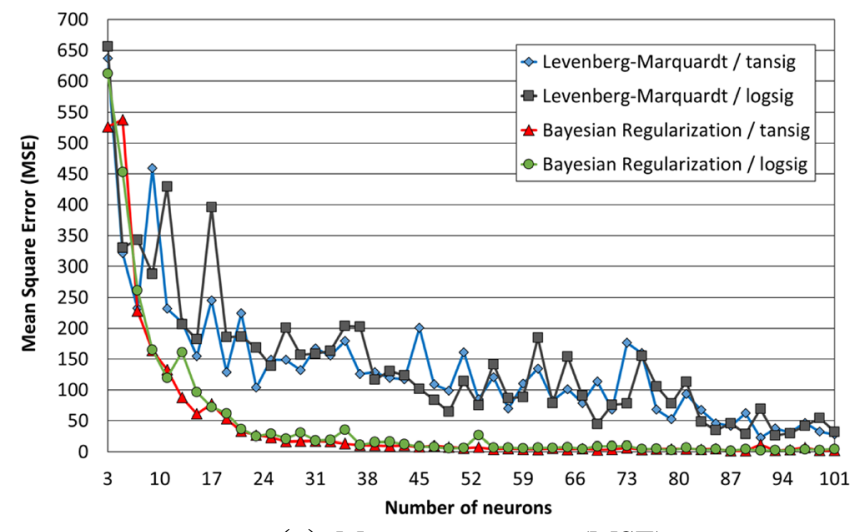

(a) Mean square error (MSE)

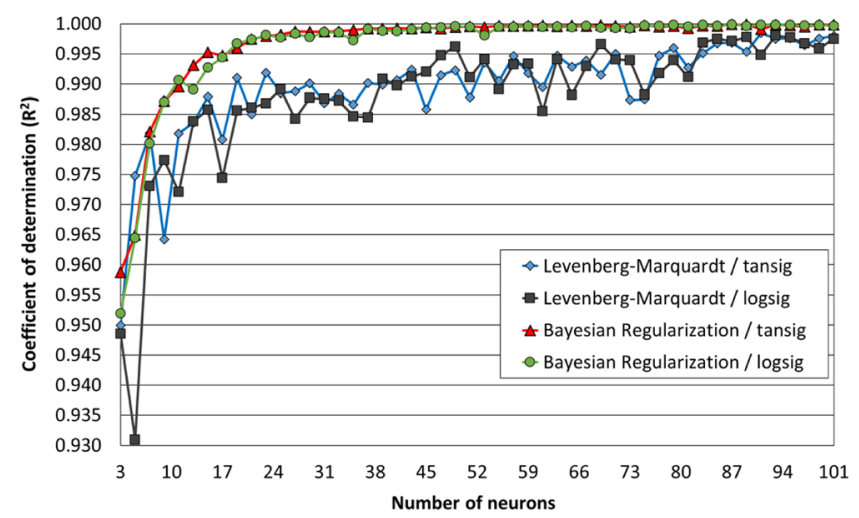

(b) Coefficient of determination $\left(\mathrm{R}^{2}\right)$

Fig. 12 Determination of optimum network architecture for different neurons in the hidden layer

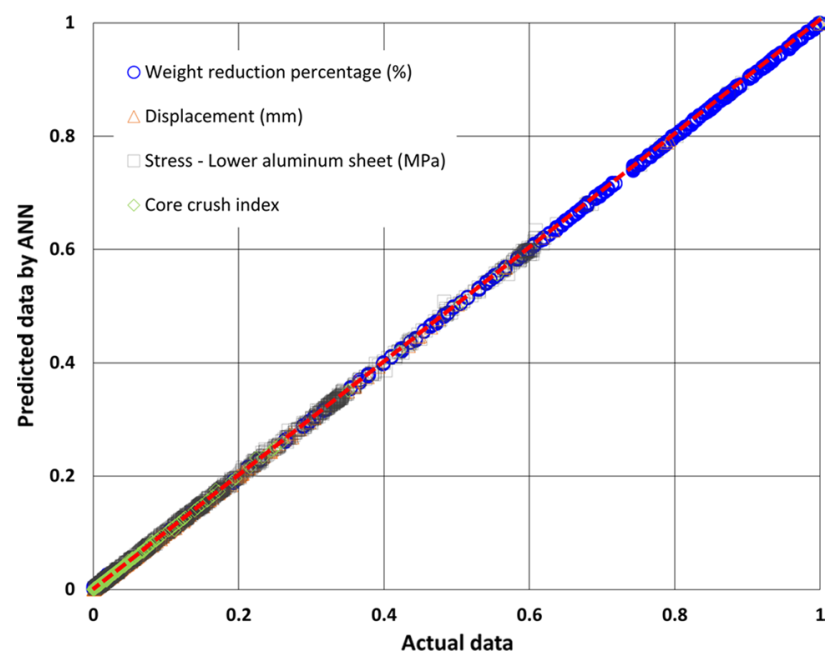

Fig. 13 Predicted values from the established ANN model versus the actual values for all datasets

\subsubsection{Predictive Performance of the ANN Model Within the Training Dataset Bounds}

In order to demonstrate the flexibility of the ANN model, the model was tested for its ability to predict the structural performance of the heliostat based on an unseen dataset within the training bounds. For a heliostat panel subjected to a wind of $20 \mathrm{~m} / \mathrm{s}$ and consisting of a honeycomb core with a thickness $(D)$ of $300 \mathrm{~mm}$, Figs. 14 and 15 demonstrate the cell geometry effect and the structural performance predictions made by the ANN model at multiple cell wall angles for unseen honeycomb cell wall thicknesses $(t)$ of $0.025,0.035$ and $0.045 \mathrm{~mm}$.

Starting with the case when the heliostat panel consists of a honeycomb core with cell wall angle $(\varphi)$ of $10^{\circ}$, the panel experiences the maximum structural deformation and stress values when the honeycomb's cell wall thickness is of $t=0.02 \mathrm{~mm}$. At this configuration $\left(\varphi=10^{\circ}, t=0.02 \mathrm{~mm}\right)$, the resultant deformation and stresses at both the lower aluminium sheet and the aluminium honeycomb core were found to increase with the increase in the honeycomb's cell wall length $(a)$. As previously discussed, weight savings are achieved by increasing the cell wall length. This is due to the fact that as the honeycomb's cell wall length increases; the honeycomb cells become less dense, and the area fraction of non-load-carrying cell walls increases. However, it needs to be tempered against the fact that this results in a reduction in the Young's modulus of the honeycomb core, resulting in a less stiff heliostat panel with less resistance to wind loads.

Both the displacement and stress values dramatically decrease as the honeycomb's cell wall thickness $(t)$ increases from $t=0.02 \mathrm{~mm}$ to $t=0.03 \mathrm{~mm}$ for the same $10^{\circ}$ cell wall angle results and all cell wall lengths. As previously described, the honeycomb's cell walls' bending resistance increases with the increase in thickness, causing an increase in the heliostat panel's stiffness and resistance to local buckling and crushing. Moreover, it is apparent from the results that a further increase in the cell wall thickness has a slight influence on the heliostat's structural performance, and as the cell wall thickness gradually increases from $t=0.03 \mathrm{~mm}$ to $t=0.05 \mathrm{~mm}$, the displacement and stress values do slightly decrease. This slight improvement in the structural performance comes with a substantial increase in the overall weight of the honeycomb core.

The maximum displacement and stress results for a heliostat panel that consists of a core with $\varphi=30^{\circ}$ revealed the same patterns of variation seen in the $10^{\circ}$ cell wall angle configuration but lower in magnitudes. This reduction caries on as the cell wall angle progressively increases until it reaches $\varphi=50^{\circ}$ for all cell wall lengths. Having said that, the trend in weight savings does not follow the same pattern and instead, it exhibits a notable increase in the attained weight reduction as the honeycomb's cell wall angle $(\varphi)$ 


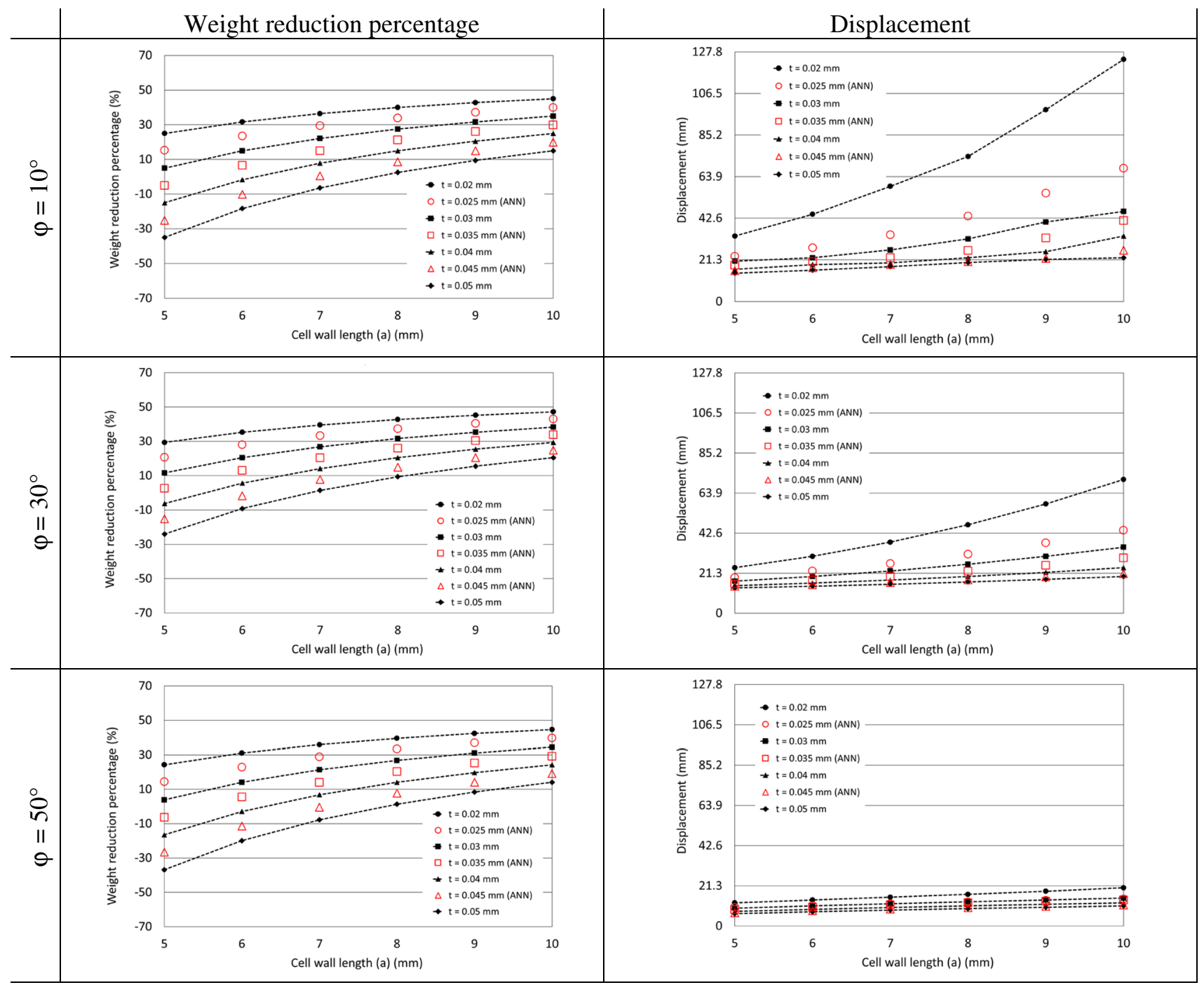

Fig. 14 ANN model predictions of the heliostat's attainable weight reduction and maximum structural displacement at multiple cell wall angles for unseen cell wall thicknesses of $0.025,0.035$ and $0.045 \mathrm{~mm}$

changes from $\varphi=10^{\circ}$ and $\varphi=50^{\circ}$ to $\varphi=30^{\circ}$ as a result of the increase in the void between the cell walls.

As demonstrated in the results for the unseen honeycomb cell wall thicknesses $(t)$ of $0.025,0.035$ and $0.045 \mathrm{~mm}$, the ANN model's predictions lie between the two limits bounding each of the investigated unseen cell wall thicknesses, as one might expect. This provides confidence that the model is behaving correctly.

\subsubsection{Predictive Performance of the ANN Model Outside the Training Dataset Bounds}

Previously, it was shown that the ANN provided accurate predictions within the bounds of the data it was trained. Having said that, if the ANN model is provided with inputs outside the training set's bounds, one would anticipate less accurate predictions. With a robust network, the model should be capable of delivering insights that would be difficult to realize by traditional approaches. Therefore, to investigate the ANN model capabilities outside the training bounds, the ANN model was utilized to predict the structural performance of the sandwich composite-based heliostat that consisted of a core with honeycomb cell wall thickness of $t=0.01 \mathrm{~mm}$.

It was previously noted that a decrease in the cell wall thickness causes the panel's stiffness to decrease, and consequently, the honeycomb core becomes less resistant to local buckling and crushing. However, this decrease in stiffness comes with a notable increase in the attained weight reduction. Based on this, one would anticipate seeing the same behaviour characteristics for a heliostat that consists of a core with honeycomb cell wall thickness $t=0.01 \mathrm{~mm}$. 


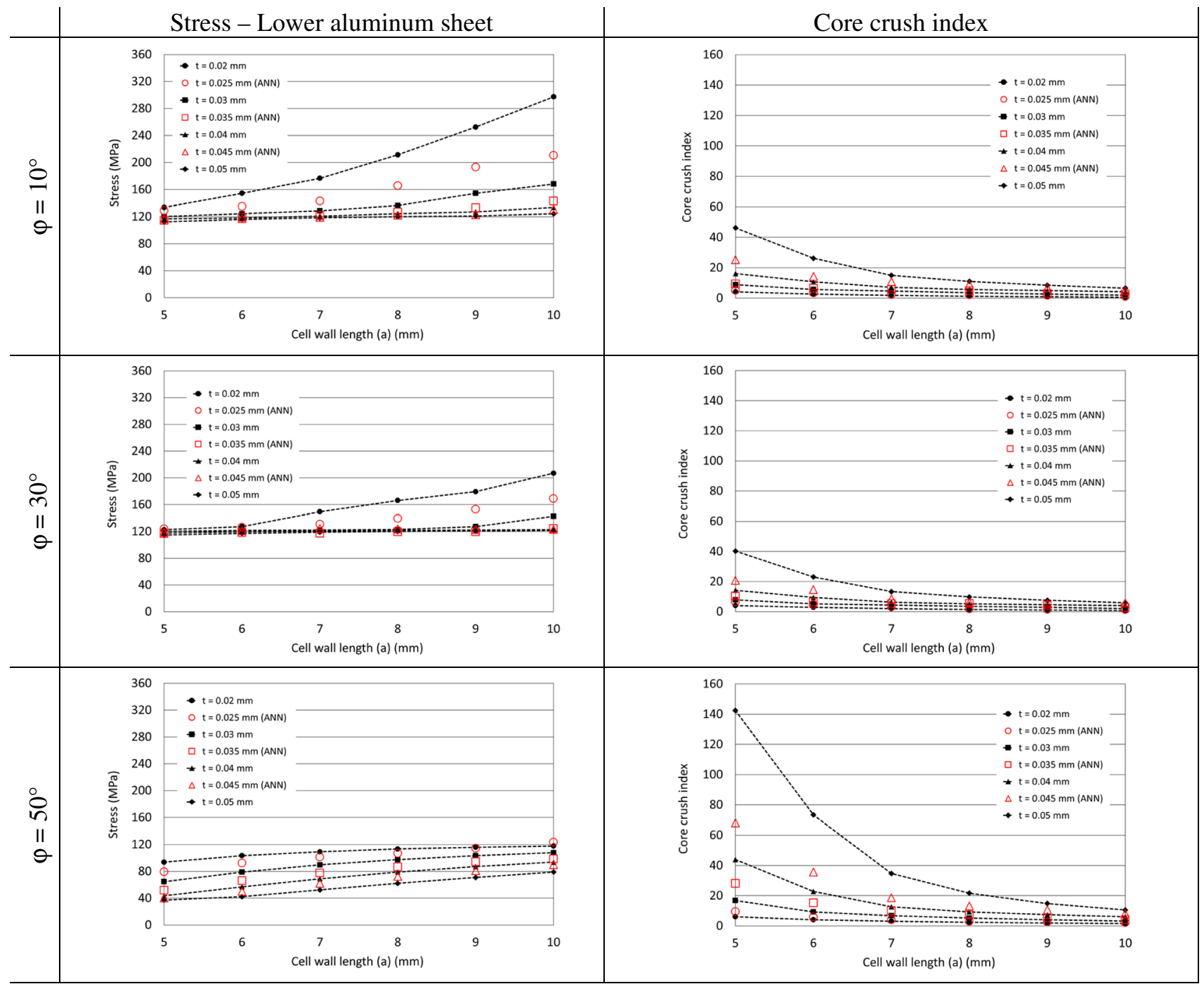

Fig. 15 ANN model predictions of the heliostat's recorded maximum stress at the lower aluminium sheet and core crush index at multiple cell wall angles for unseen cell wall thicknesses of $0.025,0.035$ and $0.045 \mathrm{~mm}$

As such, Figs. 16 and 17 show the predictions of the ANN model at multiple cell wall angles for a core with cell wall thickness $(t)$ between 0.01 and $0.05 \mathrm{~mm}$ for a heliostat subjected to a wind of $20 \mathrm{~m} / \mathrm{s}$, with a core thickness $(D)$ of $300 \mathrm{~mm}$. To fully evaluate the predictive value of the ANN model, simulations were carried out using the previously established FSI model for the same cell wall thickness $(t=0.01 \mathrm{~mm})$ and the results were compared to the ANN model predictions. The results illustrate the behaviour one would expect, demonstrating that the ANN model can provide insights into the structural performance of the heliostat with design parameters outside the training bounds.

\subsection{Heliostat Structural Optimization}

Having established an ANN model that accurately predicts the heliostat's structural performance based on its honeycomb core's configuration, attention was turned towards the structural optimization of the sandwich compositebased heliostat by integrating the PSO algorithm with the ANN. As discussed earlier, the swarm size is an adjustable parameter and is determined by the algorithm's performance. In this regard, and having set up the optimization scheme, the effect of the swarm size (number of particles) on the optimization performance was investigated to find the number of particles that delivered the best performance for convergence and processing time.

Figure 18 demonstrates the objective function evolution (weight reduction percentage) for Configuration 1 in 


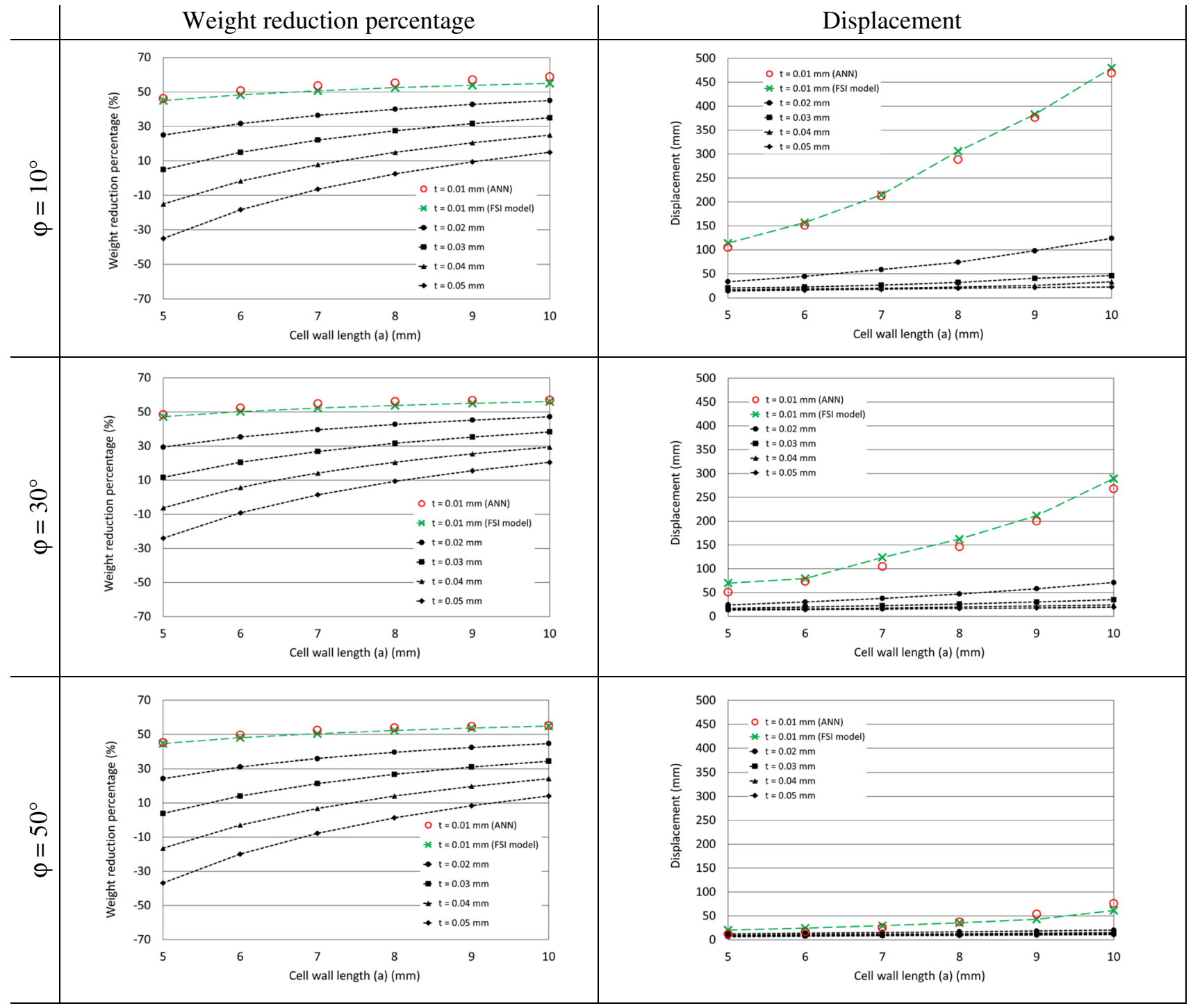

Fig. 16 ANN model predictions of the heliostat's attainable weight reduction and maximum structural displacement at multiple cell wall angles for unseen cell wall thickness $0.01 \mathrm{~mm}$

Table 1 as a function of the number of iterations realized for various swarm sizes. From to the results, the most obvious conclusion is that increasing the size of the swarm improves the quality of the optimum obtained. However, for swarms with more than 40 particles, there is little change in the optimal weight reduction. In this sense, a swarm size of 40 particles was selected for the optimization study.

Having identified the swarm size, attention was focused on evaluating the effectiveness of the established PSO algorithm. This evaluation was based on the comparison between of results obtained by the PSO approach and those obtained by scanning of all the search space defined by the variables to be optimized. It should be noted that high number of parameters to optimize, the dependence between them, and the existence of several local optima, makes the optimization procedure extremely complex.

In undertaking the evaluation, both algorithms were applied to the first case scenario (Configuration 1). In this case, the heliostat was subjected to a wind of $20 \mathrm{~m} / \mathrm{s}$ and was constrained such that the maximum allowable structural deformation was $21.3 \mathrm{~mm}$, the maximum allowable stress at the lower aluminium sheet was $280 \mathrm{MPa}$, and the minimum allowable core crush index was 1 .

From the space scanning method, and starting with the case when the heliostat panel consists of a honeycomb core with a thickness of $D=150 \mathrm{~mm}$, only a few honeycomb configurations have satisfied the optical criteria, 


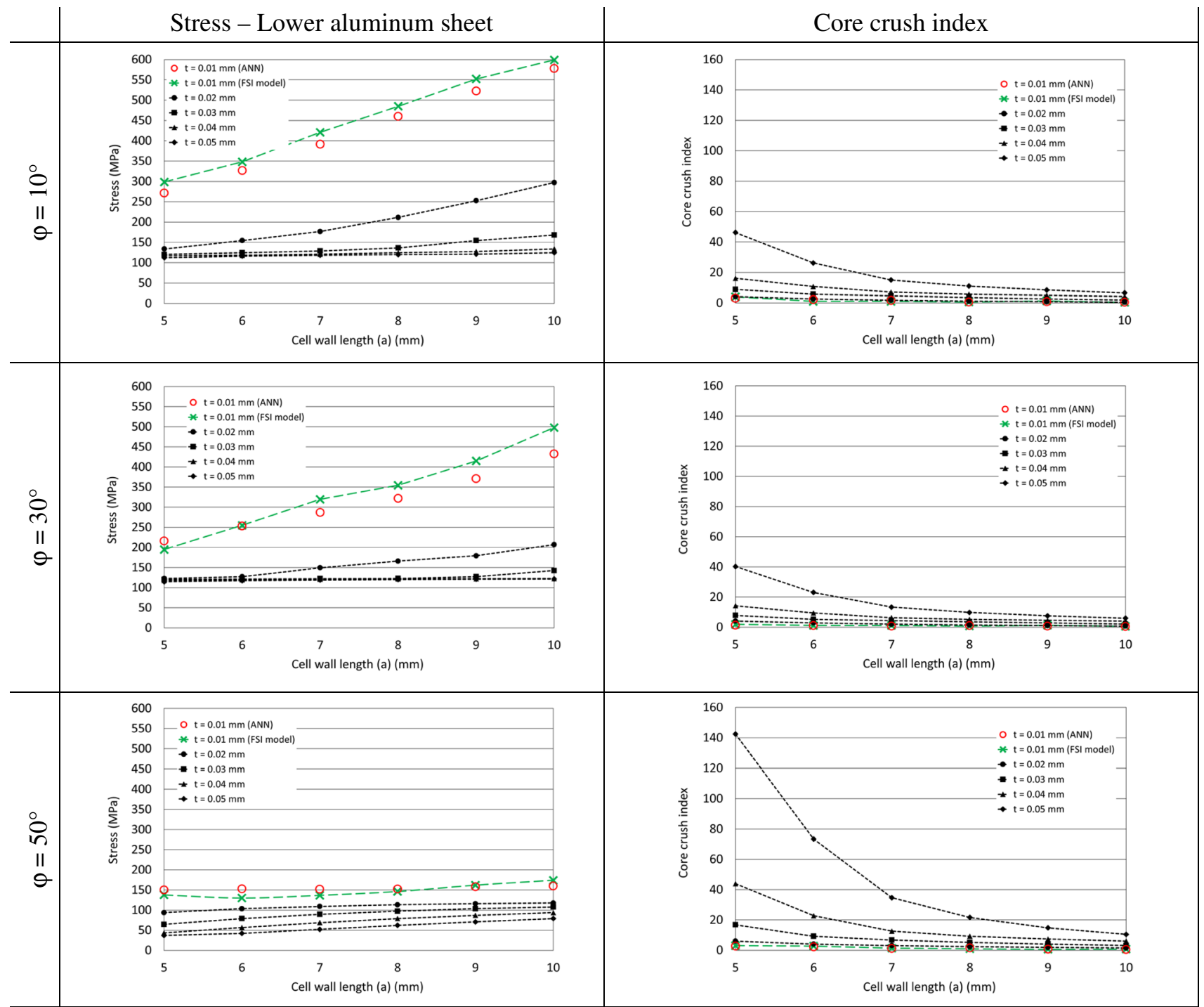

Fig. 17 ANN model predictions of the heliostat's recorded maximum stress at the lower aluminium sheet and core crush index at multiple cell wall angles for unseen cell wall thickness of $0.01 \mathrm{~mm}$

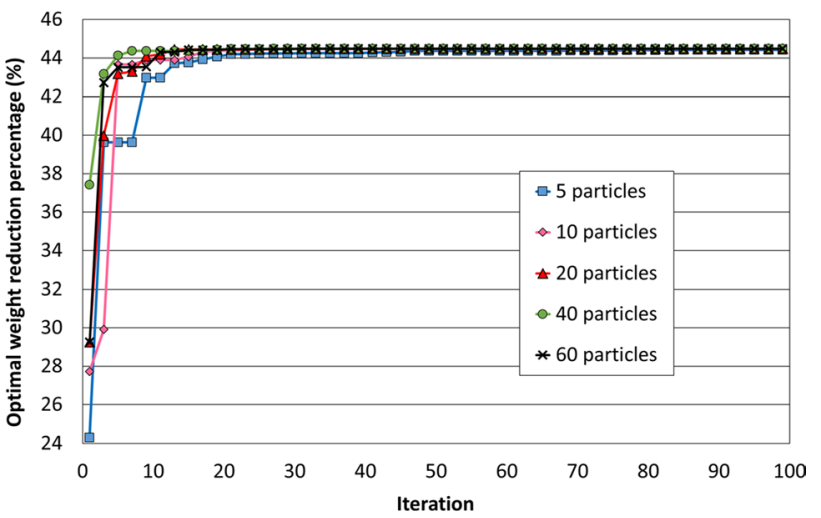

Fig. 18 Objective function evolution (weight reduction percentage) according to the number of iterations performed for various swarm sizes (case of configuration 1) with a minimum deformation of $19.27 \mathrm{~mm}$ recorded when the honeycomb's cell wall thickness $(t)$ and length $(a)$ are of $0.05 \mathrm{~mm}$ and $5 \mathrm{~mm}$, respectively. At this configuration ( $\varphi=50^{\circ}, t=0.05 \mathrm{~mm}, a=5 \mathrm{~mm}$ ), the maximum recorded stress at the lower aluminium sheet $(78.73 \mathrm{MPa})$ and the core crush index (67.2) are found to be within the permissible material failure limits. With both optical and structural strength requirements being satisfied, a weight reduction of approximately $14.07 \%$ is achieved with this core configuration.

Moving to the case when the heliostat panel consists of a honeycomb core with a thickness of $D=300 \mathrm{~mm}$, the configuration that gives most desirable trade-off between the heliostat panel's structural integrity and attained weight reduction is when the panel consists of a honeycomb core 
with cell wall angle of $\varphi=50^{\circ}$, cell wall length of $a=10 \mathrm{~mm}$ and cell wall thickness of $t=0.02 \mathrm{~mm}$, with a maximum displacement of $20.3 \mathrm{~mm}$, a maximum stress of $117.83 \mathrm{MPa}$, a core crush index value of 1.57 , and an achieved weight reduction of approximately $44 \%$. For the case when the heliostat panel consists of a honeycomb core with a thickness of $D=450 \mathrm{~mm}$, and with all the requirements being satisfied (i.e. optical, material failure and weight reduction), a heliostat panel with a core configuration of $\varphi=50^{\circ}, a=10 \mathrm{~mm}$ and $t=0.02 \mathrm{~mm}$ provides a sensible trade-off between the panel's structural integrity and weight reduction percentage, with a maximum displacement of $12.21 \mathrm{~mm}$, a maximum stress of $83.1 \mathrm{MPa}$, a core crush index value of 4.13 and an attained weight reduction of approximately $34.45 \%$.

From these results, it can be concluded that among the various honeycomb core configurations investigated earlier using the search space scanning method, one stood out distinctively in terms of providing the most desirable tradeoff between the heliostat panel's structural integrity and attained weight saving ( $44 \%$ weight reduction percentage). This configuration is when the heliostat panel consists of a honeycomb core with a thickness $(D)$ of $300 \mathrm{~mm}$, cell wall angle $(\varphi)$ of $50^{\circ}$, cell wall length $(a)$ of $10 \mathrm{~mm}$ and cell wall thickness $(t)$ of $0.02 \mathrm{~mm}$.

For the values acquired by the ANN-PSO approach, Fig. 19 demonstrates the evolution of the honeycomb core's physical parameters [core thickness $(D)$, cell wall angle $(\varphi)$, cell wall thickness $(t)$ and the cell wall length $(a)$ ] and the weight reduction percentage along the iterative procedure. We can observe, that at the beginning, the swarm is randomly distributed and searching for the optimal honeycomb core and panel configuration, then along the iterative procedure the particles move and regroup progressively towards the optimal zone for each parameter.

It can be seen that the honeycomb core thickness, the cell wall angle, the cell wall thickness and the cell wall length converge to constant values after 60 iterations, reaching an optimum ( $D=302.91 \mathrm{~mm}, \varphi=50^{\circ}, t=0.02 \mathrm{~mm}, a=10 \mathrm{~mm}$ ) that corresponded to a weight reduction of $44.47 \%$, a maximum panel displacement of $19.6 \mathrm{~mm}$, a maximum stress at the lower aluminium sheet of $116.33 \mathrm{MPa}$ and a core crush index value of 1.99. From this, it can be noted that the PSO optimization results are in good agreement with the results attained by scanning of all the search space, proving the reliability of the approach and the selected PSO parameters.

However, this cannot be retained as a comparison between the two approaches since the computing time consumed by using the scanning method is far from ideal. A slight change in the performance requirements (constraints) can lead to a superficial adjustment in the optimal solution, but necessitates the scanning of the entire search space defined by the variables to be optimized again. Also, the scanning approach is not well suited for a higher number of parameters. For instance, if the method in the aforementioned case requires a scan resolution of $1 \%$ of the definition interval of each parameter, the number of simulations required to scan all the calculation domains is $100 \times 100 \times 100 \times 100=1 \times 1$ $0^{8}$. Whereas, via the PSO approach, the number of simulations performed is: Number of particles $\times$ Number of iterations $=40 \times 100=4000$ simulations only. This demonstrates that such limitations can be avoided by utilizing the ANNPSO approach, making this approach very attractive in terms of computational time and the capability of producing an optimum and a reliable solution.

Having demonstrated the advantages of the ANN-PSO approach, it was applied to the remaining two cases in Table 1, with the results summarized in Table 2. For Configuration 2 , it was found that changing the design requirements to reduce panel deflection and stresses at both the lower aluminium sheet and the honeycomb core resulted in an increase in the honeycomb core thickness. Although increasing the panel thickness tends to improve the structural performance of the heliostat, which may present an advantage from a structural point of view, this could represent a minor disadvantageous material cost given the increase in panel thickness and also the slight decrease in the panel's weight reduction percentage (which also broadly equates to cost). As for Configuration 3, one can observe that the reduction in the design wind speed requirement had a pronounced impact on the optimal solution. For this configuration, a heliostat panel with a reduced core thickness $(D=150 \mathrm{~mm})$ and $t=0.02 \mathrm{~mm}, a=10 \mathrm{~mm}, \varphi=47.92^{\circ}$ satisfies all the requirements (i.e. optical and material failure), with a weight saving of approximately $55 \%$.

This finding is extremely significant as it implies that heliostats near the centre of a heliostat field, which are subject to lower local wind speeds, can be made to be much lighter. This could lead to reductions in the size of drive units used to track the heliostat, and the foundations required to support these structures. Such reductions would deliver real cost savings, which are currently an impediment to the wider spread use of CSP systems.

\section{Conclusion}

The present study was undertaken to investigate the utilization of artificial neural network (ANN) technique and particle swarm optimization (PSO) algorithm to establish a novel prediction-optimization (ANN-PSO) model that predicts the structural performance of honeycomb sandwich compositebased heliostats, and determines the optimum honeycomb core configuration leading to minimum self-weight of the heliostat's sandwich composite panel while satisfying the structural performance requirements (i.e. optical and material failure). 


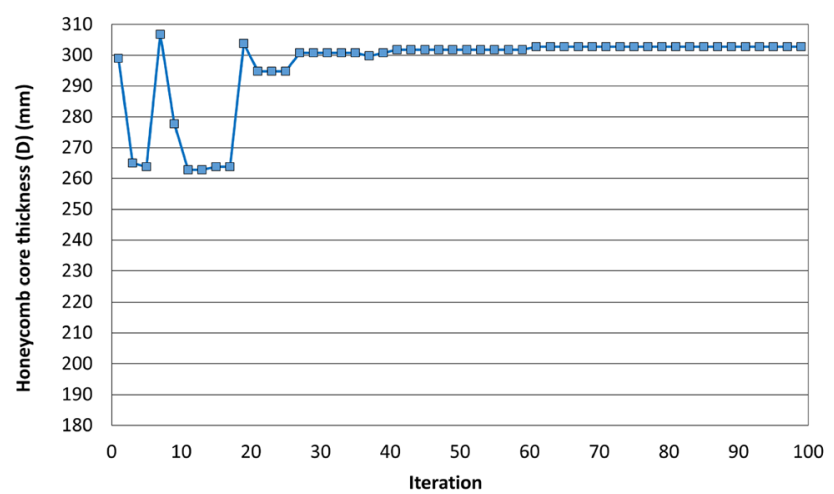

Honeycomb core thickness (D)

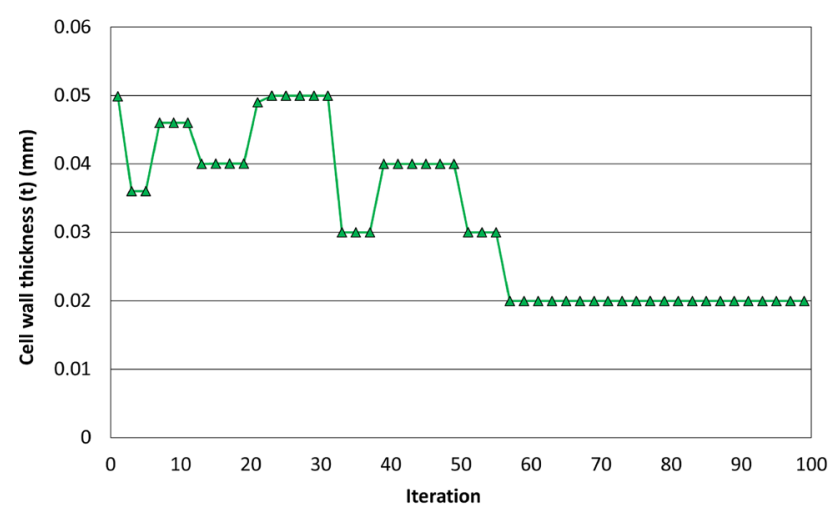

Cell wall thickness ( $\mathrm{t}$ )

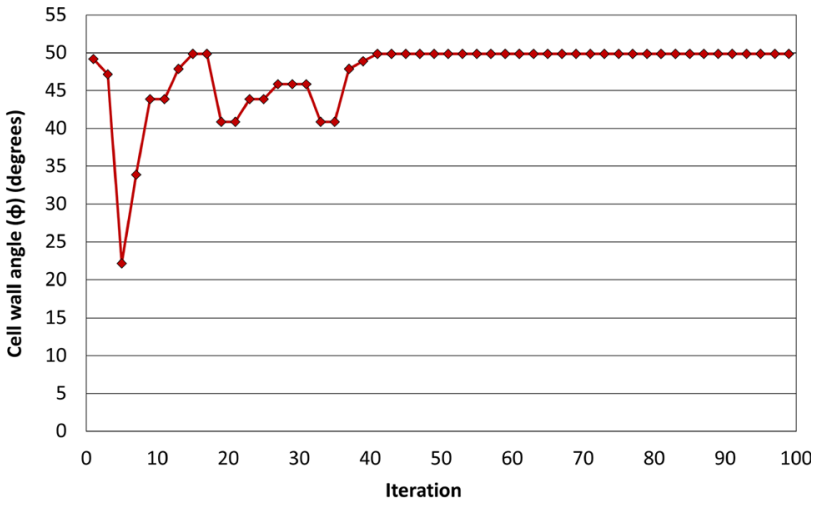

Cell wall angle $(\varphi)$

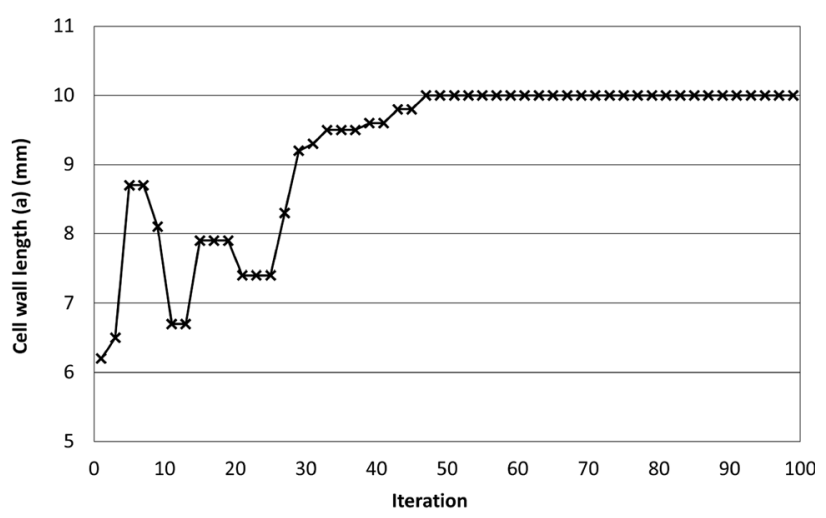

Cell wall length (a)

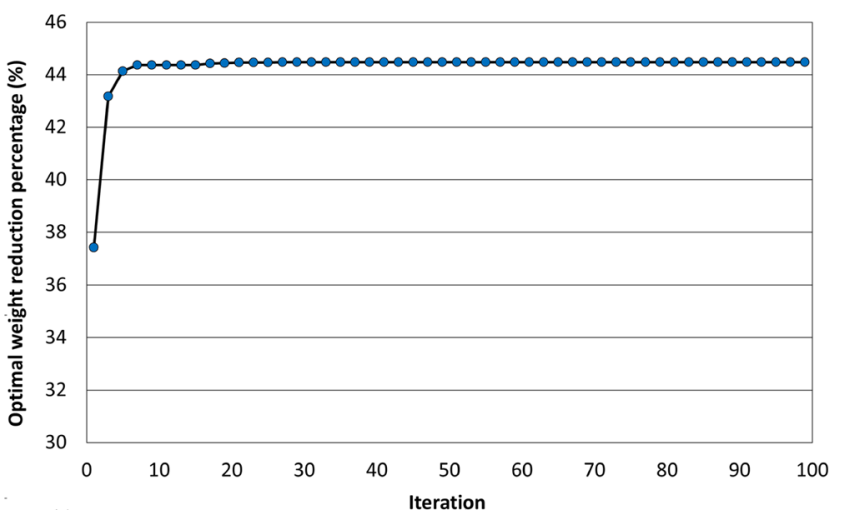

Weight reduction percentage (\%)

Fig. 19 Evolution of the optimum along the iterative procedure (case of configuration 1)

Starting with the prediction component, the ANN was trained, tested and validated by a rich dataset obtained from a comprehensive parametric study carried out with various honeycomb core configurations assessed considering several loading conditions (wind velocities of 5, 10,15 and $20 \mathrm{~m} / \mathrm{s}$ ). A thorough investigation was carried out to optimally choose the training algorithm, number of neurons in the hidden layer and activation function in a network. Among all the neural network configurations explored, a network model with Bayesian regularization
(BR) training algorithm, tansig transfer function and having 89 neurons in the hidden layer was found to be the optimum network with the best predictive performance $\left(R^{2}=0.99994, \mathrm{MSE}=0.1026\right)$. The results showed that the established ANN model was capable of predicting the structural performance of the honeycomb sandwich composite-based heliostat based on unseen honeycomb core configurations extremely accurately. Moreover, it was demonstrated that the established ANN model could deliver insights into the heliostat's structural performance 
Table 2 PSO optimization results of the three cases

\begin{tabular}{|c|c|c|c|}
\hline & Configuration 1 & Configuration 2 & Configuration 3 \\
\hline \multicolumn{4}{|l|}{ Design requirements } \\
\hline Chosen site's maximum design wind velocity (m/s) & $20 \mathrm{~m} / \mathrm{s}$ & $20 \mathrm{~m} / \mathrm{s}$ & $10 \mathrm{~m} / \mathrm{s}$ \\
\hline Maximum allowable structural deformation (mm) & $21.3 \mathrm{~mm}$ & $10 \mathrm{~mm}$ & $21.3 \mathrm{~mm}$ \\
\hline Maximum allowable stress at lower aluminium sheet $(\mathrm{MPa})$ & $280 \mathrm{MPa}$ & $100 \mathrm{MPa}$ & $280 \mathrm{MPa}$ \\
\hline Minimum allowable core crush index & 1 & 5 & 1 \\
\hline \multicolumn{4}{|l|}{ Optimized honeycomb core parameters } \\
\hline Core thickness $(D)(\mathrm{mm})$ & 302.91 & 351.44 & 150 \\
\hline Cell wall angle $(\varphi)$ (degree) & 50 & 50 & 47.92 \\
\hline Cell wall thickness $(t)(\mathrm{mm})$ & 0.02 & 0.02 & 0.02 \\
\hline Cell wall length $(a)(\mathrm{mm})$ & 10 & 10 & 10 \\
\hline \multicolumn{4}{|l|}{ Structural performance } \\
\hline Optimized weight reduction percentage (\%) & 44.47 & 41.64 & 55.23 \\
\hline Panel displacement & 19.6 & 8.3 & 19.6 \\
\hline Stress-aluminium sheet & 116.33 & 64.1 & 49.31 \\
\hline Core crush index & 1.99 & 7.35 & 3.25 \\
\hline
\end{tabular}

with design parameters outside the training bounds. Given the capability and flexibility of the ANN technique, it demonstrates a unique and novel alternative method to designing and analysing the structural performance of honeycomb sandwich composite-based heliostats. This is of particular significance as accurately predicting the heliostat's structural performance based on its honeycomb core's configuration using classical analytical approaches are at best cumbersome and, at worst, unable to facilitate the predications.

Moving to the optimization component, a rigorous investigation was carried out to optimally choose the suitable swarm size (number of particles) that delivers the best performance for convergence and processing time. It was found that increasing the size of the swarm greater than 40 particles does not further improve the quality of the optimum obtained. In this sense, a swarm size of 40 particles was selected for the optimization study. The optimization process was carried out for three case scenarios, each with different design requirements, to demonstrate the feasibility of the proposed approach for this system. The results showed that the proposed integrated ANN-PSO approach, which can also be encompassed as a user-friendly graphical user interface (GUI), provides a useful, flexible and time-efficient tool for heliostat designers to predict and optimize the structural performance of honeycomb sandwich composite-based heliostats as per desired requirements.

\section{Declarations}

Conflict of interest The authors declare that there is no conflict of interest regarding the publication of this article.
Open Access This article is licensed under a Creative Commons Attribution 4.0 International License, which permits use, sharing, adaptation, distribution and reproduction in any medium or format, as long as you give appropriate credit to the original author(s) and the source, provide a link to the Creative Commons licence, and indicate if changes were made. The images or other third party material in this article are included in the article's Creative Commons licence, unless indicated otherwise in a credit line to the material. If material is not included in the article's Creative Commons licence and your intended use is not permitted by statutory regulation or exceeds the permitted use, you will need to obtain permission directly from the copyright holder. To view a copy of this licence, visit http://creativecommons.org/licenses/by/4.0/.

\section{References}

1. Goswami, D.Y.: Principles of solar engineering, 3rd edn. CRC Press, New York, USA (2015)

2. Islam, M.T.; Huda, N.; Abdullah, A.B.; Saidur, R.: A comprehensive review of state-of-the-art concentrating solar power (CSP) technologies: current status and research trends. Renew. Sustain. Energy Rev. 91, 987-1018 (2018)

3. Serradj, D.B., Sebitosi, A.B., Fadlallah, S.O.: Design and performance analysis of a parabolic trough power plant under the climatological conditions of Tamanrasset, Algeria. Int. J. Environ. Sci. Technol. 1-18 (2021)

4. Behar, O.; Khellaf, A.; Mohammedi, K.: A review of studies on central receiver solar thermal power plants. Renew. Sustain. Energy Rev. 23, 12-39 (2013)

5. Hinkley, J.T.; Hayward, J.A.; Curtin, B.; Wonhas, A.; Boyd, R.; Grima, C.; Tadros, A.; Hall, R.; Naicker, K.: An analysis of the costs and opportunities for concentrating solar power in Australia. Renew. Energy 57, 653-661 (2013)

6. Kolb, G., Jones, S., Donnelly, M., Gorman, D., Thomas, R., Davenport, R., Lumia, R.:Heliostat cost reduction study. Sandia National Laboratories, Albuquerque, New Mexico, Report number SAND2007-3293 (2007). Available from <http://prod.sandia.gov/ techlib/access-control.cgi/2007/073293.pdf $>$. 
7. Mancini, T.R.: Catalog of solar heliostats. SolarPACES report No. III-1/00 (2000). Available from <http://www.fika.org/jb/resou rces/Heliostat\%20Catalog.pdf $>$.

8. Pfahl, A.; Coventry, J.; Röger, M.; Wolfertstetter, F.; VásquezArango, J.F.; Gross, F.; Arjomandi, M.; Schwarzbözl, P.; Geiger, M.; Liedke, P.: Progress in heliostat development. Sol. Energy 152, 3-37 (2017)

9. Hu, Y.; Xu, Z.; Zhou, C.; Du, J.; Yao, Y.: Design and performance analysis of a multi-reflection heliostat field in solar power tower system. Renew. Energy 160, 498-512 (2020)

10. Schulte, D.; Krieger, K.; Chin, C.W.; Sonn, A.: Low cost, high accuracy $1.5 \mathrm{~m}^{2}$ heliostat. AIP Conf. Proc. 2303(1), 030032 (2020)

11. Davila-Peralta, C.; Rademacher, M.; Emerson, N.; Chavez-Lopez, G.; Sosa, P.; Cabanillas, R.; Peon-Anaya, R.; Flores-Montijo, N.; Didato, N.; Angel, R.: Progress in track-mounted heliostat. AIP Conf. Proc. 2303(1), 030011 (2020)

12. Peterka, J.A., Hosoya, N., Bienkiewicz, B., Cermak, J.E.: Wind load reduction for heliostats. Report SERI/STR-253-2859. Solar Energy Research Institute, Golden, Colorado, USA (1986). Available from <https://www.nrel.gov/docs/legosti/old/2859.pdf $>$.

13. Peterka, J. A., Derickson, R. G.: Wind load design methods for ground-based heliostats and parabolic dish collectors. Report number SAND92-7009. Sandia National Laboratories, Albuquerque, NM (United States) (1992).

14. Pfahl, A.; Buselmeier, M.; Zaschke, M.: Wind loads on heliostats and photovoltaic trackers of various aspect ratios. Sol. Energy 85(9), 2185-2201 (2011)

15. Bendjebbas, H.; Abdellah-ElHadj, A.; Abbas, M.: Full-scale, wind tunnel and CFD analysis methods of wind loads on heliostats: a review. Renew. Sustain. Energy Rev. 54, 452-472 (2016)

16. Diver, R.B., Grossman, J.W.: Sandwich construction solar structural facets. Sandia National Laboratories, Albuquerque, New Mexico, Report Number SAND98-2845C (1998)

17. Aldaz, L.; Burisch, M.; Zaversky, F.; Sánchez, M.; Villasante, C.; Olasolo, D.: Heliostat structural optimization: a study of wind load effects with CFD-FEM methods. AIP Conf. Proc. 2033(1), 210001 (2018)

18. Liedke, P.; Pfahl, A.; Vásquez-Arango, J.F.; Hölle, E.: 3rd generation rim drive heliostat with monolithic sandwich panel. AIP Conf. Proc. 2033(1), 040021 (2018)

19. Redmann, A.; Montoya-Ospina, M.C.; Karl, R.; Rudolph, N.; Osswald, T.A.: High-force dynamic mechanical analysis of composite sandwich panels for aerospace structures. Compos. Part C: Open Access 5, 100136 (2021)

20. Li, Q.Q.; Li, E.; Chen, T.; Wu, L.; Wang, G.Q.; He, Z.C.: Improve the frontal crashworthiness of vehicle through the design of front rail. Thin-Walled Struct. 162, 107588 (2021)

21. Palomba, G., Epasto, G., Crupi, V.: Lightweight sandwich structures for marine applications: a review. Mech. Adv. Mater. Struct. $1-26(2021)$

22. Shifa, M.; Tariq, F.; Chandio, A.D.: Mechanical and electrical properties of hybrid honeycomb sandwich structure for spacecraft structural applications. J. Sandwich Struct. Mater. 23(1), 222-240 (2021)

23. Paik, J.K.; Thayamballi, A.K.; Kim, G.S.: The strength characteristics of aluminum honeycomb sandwich panels. Thin-Walled Struct. 35(3), 205-231 (1999)

24. Heimbs, S.; Vogt, D.; Hartnack, R.; Schlattmann, J.; Maier, M.: Numerical simulation of aircraft interior components under crash loads. Int. J. Crashworthiness 13(5), 511-521 (2008)

25. Castellon, J.: Cellular ceramics: Reinforced brick construction in the digital age. Interceram 61(5), 277-282 (2012)

26. Cheng, S.; Qiao, P.; Chen, F.: Numerical analysis of I-Lam honeycomb sandwich panels for collision protection of reinforced concrete beams. J. Sandwich Struct. Mater. 1, 1-26 (2016)
27. Fadlallah, S., Anderson, T., Nates, R.: Structural deformation of sandwich composite heliostats. Proceedings of the Asia Pacific Solar Research Conference 2018 (APSRC 2018), Sydney, Australia (2018)

28. Galgalikar, R.: Design automation and optimization of honeycomb structures for maximum sound transmission loss, Master's thesis, Clemson University, South Carolina, United States of America (2012)

29. Yamashita, M.; Gotoh, M.: Impact behavior of honeycomb structures with various cell specifications-numerical simulation and experiment. Int. J. Impact Eng. 32(1-4), 618-630 (2005)

30. Ivañez, I.; Fernandez-Cañadas, L.M.; Sanchez-Saez, S.: Compressive deformation and energy-absorption capability of aluminium honeycomb core. Compos. Struct. 174, 123-133 (2017)

31. Ajdad, H.; Baba, Y.F.; Al Mers, A.; Merroun, O.; Bouatem, A.; Boutammachte, N.: Particle swarm optimization algorithm for optical-geometric optimization of linear Fresnel solar concentrators. Renew. Energy 130, 992-1001 (2019)

32. Elsheikh, A.H.; Elaziz, M.A.: Review on applications of particle swarm optimization in solar energy systems. Int. J. Environ. Sci. Technol. 16, 1159-1170 (2019)

33. Lahiri, S.K.; Ghanta, K.C.: Artificial neural network model with the parameter tuning assisted by a differential evolution technique: the study of the hold up of the slurry flow in a pipeline. Chem. Ind. Chem. Eng. Q. 15(2), 103-117 (2009)

34. Pandey, D.S.; Das, S.; Pan, I.; Leahy, J.J.; Kwapinski, W.: Artificial neural network based modelling approach for municipal solid waste gasification in a fluidized bed reactor. Waste Manag. 58, 202-213 (2016)

35. Azizi, S.; Awad, M.M.; Ahmadloo, E.: Prediction of water holdup in vertical and inclined oil-water two-phase flow using artificial neural network. Int. J. Multiph. Flow 80, 181-187 (2016)

36. Baughman, D.R.; Liu, Y.A.: Neural Networks in Bioprocessing and Chemical Engineering. Academic press, New York, USA (1995)

37. Kumar, R.; Aggarwal, R.K.; Sharma, J.D.: Comparison of regression and artificial neural network models for estimation of global solar radiations. Renew. Sustain. Energy Rev. 52, 1294-1299 (2015)

38. Kan, C.W.; Song, L.J.: An artificial neural network model for prediction of colour properties of knitted fabrics induced by laser engraving. Neural Process. Lett. 44, 639-650 (2016)

39. Lanzi, L.; Bisagni, C.; Ricci, S.: Neural network systems to reproduce crash behavior of structural components. Comput. Struct. 82(1), 93-108 (2004)

40. Li, J.; Chen, X.; Wang, H.: Comparison of artificial neural networks with response surface models in characterizing the impact damage resistance of sandwich airframe structures. 2009 Second Int. Symp. Comput. Intell. Des. 2, 210-215 (2009)

41. Sun, G.; Li, G.; Stone, M.; Li, Q.: A two-stage multi-fidelity optimization procedure for honeycomb-type cellular materials. Comput. Mater. Sci. 49(3), 500-511 (2010)

42. Esfahlani, S.S.; Shirvani, H.; Shirvani, A.; Nwaubani, S.; Mebrahtu, H.; Chirwa, C.: Hexagonal honeycomb cell optimisation by way of meta-model techniques. Int. J. Crashworthiness 18(3), 264-275 (2013)

43. Baykasoğlu, A.; Baykasoğlu, C.: Multiple objective crashworthiness optimization of circular tubes with functionally graded thickness via artificial neural networks and genetic algorithms. Proc. Inst. Mech. Eng. C J. Mech. Eng. Sci. 231(11), 2005-2016 (2016)

44. Rodriguez-Ramirez, J.D.D., Castanié, B., Bouvet, C.: Analysis of nonlinear behavior on honeycomb cores. 21 st International Conference on Composite Materials (ICCM 21), hal-02177061 (2017)

45. Rodriguez-Ramirez, J.D.D.; Castanie, B.; Bouvet, C.: Experimental and numerical analysis of the shear nonlinear behaviour of 
Nomex honeycomb core: application to insert sizing. Compos. Struct. 193, 121-139 (2018)

46. Lan, X.K.; Huang, Q.; Zhou, T.; Feng, S.S.: Optimal design of a novel cylindrical sandwich panel with double arrow auxetic core under air blast loading. Def. Technol. 16(3), 617-626 (2020)

47. Chowdhary, S., Tafesse, B., Babu, A.A., Muthukumaran, G.: Prediction of influences of MWCNT fillers on the vibration characteristics of laminated hybrid honeycomb core sandwich GFRP composite plate. Mater. Today: Proc. 1-6 (2021).

48. Goldberg, D.E.: Genetic Algorithms in Search, Optimization and Machine Learning. Addison Wesley Longman Publishing Co., Inc., New York, USA (1989)

49. Dorigo, M.; Di Caro, G.: Ant colony optimization: a new metaheuristic. IEEE Congr Evolut Comput (CEC) 2, 1470-1477 (1999)

50. Passino, K.M.: Biomimicry of bacterial foraging for distributed optimization and control. IEEE Control Syst. Mag. 22(3), 52-67 (2002)

51. Karaboga, D.; Basturk, B.: A powerful and efficient algorithm for numerical function optimization: artificial bee colony (ABC) algorithm. J. Global Optim. 39, 459-471 (2007)

52. Kennedy, J.; Eberhart, R.: Particle swarm optimization. IEEE Int. Conf. Neural Netw. (ICNN) 4, 1942-1948 (1995)

53. Assarzadeh, Z.; Naghsh-Nilchi, A.R.: Chaotic particle swarm optimization with mutation for classification. J. Med. Signals Sens 5(1), 12-20 (2015)

54. Tao, W.; Liu, Z.; Zhu, P.; Zhu, C.; Chen, W.: Multi-scale design of three dimensional woven composite automobile fender using modified particle swarm optimization algorithm. Compos. Struct. 181, 73-83 (2017)

55. AlRashidi, M.R.; El-Hawary, M.E.: A survey of particle swarm optimization applications in electric power systems. IEEE Trans. Evol. Comput. 13(4), 913-918 (2009)

56. Hasanien, H.M.: Particle swarm design optimization of transverse flux linear motor for weight reduction and improvement of thrust force. IEEE Trans. Industr. Electron. 58(9), 4048-4056 (2010)

57. Li, H.; Chandrashekhara, K.: Particle swarm-based structural optimization of laminated composite hydrokinetic turbine blades. Eng. Optim. 47(9), 1191-1207 (2015)

58. Liu, Z.; Lu, J.; Zhu, P.: Lightweight design of automotive composite bumper system using modified particle swarm optimizer. Compos. Struct. 140, 630-643 (2016)

59. Yin, H.; Wen, G.; Gan, N.: Crashworthiness design for honeycomb structures under axial dynamic loading. Int. J. Comput. Methods 8(4), 863-877 (2011)

60. Ebrahimi, S.; Vahdatazad, N.: Multiobjective optimization and sensitivity analysis of honeycomb sandwich cylindrical columns under axial crushing loads. Thin-Walled Struct. 88, 90-104 (2015)

61. He, Q.; Ma, D.W.: Parametric study and multi-objective crashworthiness optimisation of reinforced hexagonal honeycomb under dynamic loadings. Int. J. Crashworthiness 20(5), 495-509 (2015)
62. He, Q.; Ma, D.; Zhang, Z.; Yao, L.: Mean compressive stress constitutive equation and crashworthiness optimization design of three novel honeycombs under axial compression. Int. J. Mech. Sci. 99, 274-287 (2015)

63. Xie, S.; Li, H.; Yang, C.; Yao, S.: Crashworthiness optimisation of a composite energy-absorbing structure for subway vehicles based on hybrid particle swarm optimisation. Struct. Multidiscip. Optim. 58, 2291-2308 (2018)

64. Li, C.; Zhai, R.; Yang, Y.: Optimization of a heliostat field layout on annual basis using a hybrid algorithm combining particle swarm optimization algorithm and genetic algorithm. Energies 10(11), 1924 (2017)

65. Li, C.; Zhai, R.; Liu, H.; Yang, Y.; Wu, H.: Optimization of a heliostat field layout using hybrid PSO-GA algorithm. Appl. Therm. Eng. 128, 33-41 (2018)

66. Awan, A.B.; Mouli, K.V.C.; Zubair, M.: Performance enhancement of solar tower power plant: a multi-objective optimization approach. Energy Convers Manag 225, 113378 (2020)

67. Kiwan, S., Khammash, A.L.: Optical performance of a novel tworeceiver solar central tower system. J. Sol. Energy Eng. 142(1) (2020)

68. Rizvi, A.A.; Danish, S.N.; El-Leathy, A.; Al-Ansary, H.; Yang, D.: A review and classification of layouts and optimization techniques used in design of heliostat fields in solar central receiver systems. Sol. Energy 218, 296-311 (2021)

69. Téllez, F., Burisch, M., Villasente, C., Sánchez, M., Sansom, C., Kirby, P., Turner, P., Caliot, C., Ferriere, A., Bonanos, C.A., Papanicolas, C., Montenon, A., Monterreal, R., Fernández, J.: State of the art in heliostats and definition of specifications: Survey for a low cost heliostat development. STAGE-STE Project Report (2014)

70. Araújo, H.; Leite, M.; Ribeiro, A.R.; Deus, A.M.; Reis, L.; Vaz, M.F.: The effect of geometry on the flexural properties of cellular core structures. Proc. Inst. Mech. Eng. Part L: J. Mater. Des. Appl. 233(3), 338-347 (2019)

71. Rumsey-Hill, N.; Pottas, J.; Coventry, J.: Design of efficient stamped mirror facets using topography optimisation. AIP Conf. Proc. 2126(1), 030048 (2019)

72. Khalid, A.; Latif, M.A.; Adnan, M.: An approach to estimate the duration of software project through machine learning techniques. Gomal Univ. J. Res. 33(1), 47-59 (2017)

73. Sharma, N.; Siddhartha, V.: Stochastic techniques used for optimization in solar systems: a review. Renew. Sustain. Energy Rev. 16(3), 1399-1411 (2012)

74. Björkman, N.: Heliostat design. Master Thesis, Department of Industrial Engineering and Management, KTH Royal Institute of Technology, Stockholm, Sweden (2014). 